\title{
Nanocomposite Obtained in the Plasma of a Pulsed High Voltage Discharge Using Nickel Electrodes and PTFE
}

\author{
V.G. Kuryavyi ${ }^{1 *}$, G.A. Zverev ${ }^{1}$, I.A. Tkachenko ${ }^{1}$, A.B. Slobodyuk ${ }^{1}$, A.V. Gerasimenko ${ }^{1}$, \\ A.Yu. Ustinov ${ }^{1}$, V.M. Bouznik ${ }^{1,2}$ \\ ${ }^{1}$ Institute of Chemistry FEB RAS, Vladivostok, 690022, Russia \\ ${ }^{2}$ All-Russian Research Institute of Aviation Materials, Moscow, Russia
}

${ }^{*}$ Corresponding author email: kvg@ich.dvo.ru

Received: 02 August 2021 / Revised: 21 September 2021 / Accepted: 27 September 2021 / Published: 10 October 2021

\begin{abstract}
In the plasma of pulsed high-voltage discharge, initiated between nickel electrodes in air, when the fluoroplastic is placed in the discharge gap, powder nanocomposite material has been synthesized. The nanocomposite contains $\mathrm{NiF}_{2}$ nanoparticles less than $5 \mathrm{~nm}$ in size, dispersed in a matrix consisting of carbon and fluorocarbon substances. The carbonaceous substance contains nanoscale disordered graphite-like regions. The fluorocarbon component of the composite contains fragments of PTFE molecules and fluorocarbon molecular fragments that differ in structure from PTFE molecule's structure. After annealing the composite in air at $773 \mathrm{~K}$, the initial nanocomposite is transformed into a nanocomposite containing nanosized PTFE and nanoparticles of $\mathrm{NiF}_{2}$ less than $5 \mathrm{~nm}$ in size, scattered in a matrix composed of nanographite and low-layer nanosized graphene, after aneling at $1173 \mathrm{~K}$ into a material containing $\mathrm{NiO}$ nanoparticles less than $10 \mathrm{~nm}$ in size. After annealing of the initial nanocomposite in argon atmosphere at $1073 \mathrm{~K}$, the obtained nanocomposite contains $\mathrm{Ni}$ nanoparticles with sizes less than $5 \mathrm{~nm}$ and carbon and fluorocarbon components. The magnetic susceptibility of the unannealed nanocomposite is investigated. A transition to the antiferromagnetic phase at $73 \mathrm{~K}$ was detected. At $\mathrm{T}=4 \mathrm{~K}$, exchange bias interaction of the AFM / FM type takes place in the composite. There is divergence of the FC and ZFC curves, which can be explained by the presence of a superparamagnetic phase or a spin glass phase in the sample. The field dependences of the magnetic susceptibility measured at $\mathrm{T}=300 \mathrm{~K}$ show sharp changes that occur at certain values of the magnetic field. Elucidation of the nature of these changes requires additional research.
\end{abstract}

Keywords: Nanocomposites $\mathrm{NiF}_{2}$ /C/CF/PTFE, Magnetic Susceptibility, Annealed

\section{Introduction}

Composites are materials consisting of two or more mixed components (phases) with different physicochemical properties, separated by some boundaries. Nanocomposites are a composite in which one or more phases have one, two or three dimensions less than $100 \mathrm{~nm}$ [1] - [3]. The synthesis and study of nanocomposites containing substance nanoparticles in some matrices is of great interest. Much attention to such samples is due to the fact that nanoparticles have unique properties [1] - [5]. These properties can be individually manifested or make their own special contribution to the properties of nanocomposites [16].

In this work, we synthesized and studied a nanocomposite containing nickel fluoride nanoparticles with a size of about $5 \mathrm{~nm}$ scattered in a nanosized carbon-fluorocarbon matrix. Interest in such a nanocomposite is caused by the following circumstances. The composite includes $\mathrm{NiF}_{2}$. At room temperature $\mathrm{NiF}_{2}$ exhibit a rutile structure with $\mathrm{P} 42 / \mathrm{mnm}$ space group. As well as fluorides of other metals $\left(\mathrm{FeF}_{2}, \mathrm{CoF}_{2}, \mathrm{MnF}_{2}\right)$ at low temperatures, at $\mathrm{T}_{\mathrm{N}}=73.2 \mathrm{~K}, \mathrm{NiF}_{2}$ transforms into an antiferromagnetic state. In comparison with the 
Nanocomposite Obtained in the Plasma of a Pulsed High Voltage Discharge Using Nickel Electrodes and PTFE

AFM state of fluorides of other metals $\left(\mathrm{FeF}_{2}, \mathrm{CoF}_{2}, \mathrm{MnF}_{2}\right)$, the $\mathrm{AFM}$ state of nickel fluoride has its own peculiarities. At temperatures below the Néel temperature, nickel fluoride is a canted rutile-structure antiferromagnet characterized by specific relativistic Dzyaloshinsky-Moriya interaction and exhibits weak ferromagnetism [7, 8]. $\mathrm{NiF}_{2}$ has an increased magneto optic coupling coefficient [9], $\mathrm{NiF}_{2}$ is attracting attention as conversion reaction material for $\mathrm{Li}$ ion batteries due to its comparatively high voltage $(2.96 \mathrm{~V})$ and specific capacity $(554 \mathrm{mAh} / \mathrm{g})[5,7,10,11], \mathrm{NiF}_{2}$ is a cathode material for thermal batteries with a high specific power [12], $\mathrm{NiF}_{2}$ nanoparticles acted as effective pinning centers leading to enhancement of $J c$ in the superconductor $\mathrm{Bi}-2223$ system [13], $\mathrm{NiF}_{2}$ is the efficient electrode material with high window potential of $1.8 \mathrm{~V}$ for high energy and power density asymmetric supercapacitor [14], in nanosized form, nickel fluoride has special magnetic properties, the Néel temperature shifts, an exchange bias interaction is observed, nickel fluoride nanoparticles can be in a superparamagnetic state [5, 7], at all. Due to these and other properties, nickel fluoride can find application in various devices and is interesting for fundamental research.

To obtain the samples, containing nanoparticles $\mathrm{NiF}_{2}$, we used a pulsed high-voltage discharge plasma initiated between nickel electrodes with PTFE material placed in the plasma $[15,16]$. There are various other ways to obtain nanoparticles of $\mathrm{NiF}_{2}$ and other fluorides [4, 10, 11], [17] - [19]. The inconvenient features of obtaining fluorides are the use in different cases of aggressive fluorine, hydrofluoric acid, or fluorides of various metals, work with solutions of chemical substances, and the use of special nanoporous matrices in which nanoparticles are formed. Methods of salt-free and fluorine-free production of metal fluorides are currently being developed $[15,16,19]$. The production of nickel fluoride nanoparticles by our method requires only the use of nickel electrodes, PTFE rods, and a low-power high-voltage pulse generator. Thus, the advantage of our method lies in the rapid receipt of samples for research and thus does not require aggressive chemicals and gases and complex energy-intensive equipment.

Another part of this work was the annealing of the resulting composite under different conditions in air and in argon. In this simple way, nickel oxide nanoparticles and nickel nanoparticles were obtained the scattered in carbon matrix. The interest to nickel oxide nanoparticles is caused by to their magnetic, optical, catalytic and electrical properties as well as mechanical hardness, passive chemical nature and thermal stability. Nickel oxide nanoparticles are widely used in supercapacitor batteries, magnetic materials, and catalysis [20] - [22]. Ni nanoparticles are used in fields such as biomedical, catalysis, supercapacitors, and dye-sensitized solar cells [23] - [25]. Over the last decade, nickel nanoparticles have been investigated for various potential applications due to their superior ferromagnetic properties such as magneto-crystalline anisotropy, high coercive forces, and chemical stability [23] - [25]. It can be noted that the very production of nickel oxide from nickel fluoride and nickel from $\mathrm{NiF}_{2}$ by annealing in air or in argon, at temperature lowest than temperature of destruction $\mathrm{NiF}_{2}$, is an unexpected result, since fluorine is the most electronegative element. Below, we discuss the question of whether this effect is possibly related to the structure of the carbon matrix and size of $\mathrm{NiF}_{2}$ nanoparticles

Another result of annealing the initial composite in air was the formation of nanographene regions in its bulk. It is known that nanographene regions have a number of unique magnetic, electrically conductive, catalytic and other properties and are promising building blocks for electronic devices [6, 26].

\section{Materials and Methods}

Samples were prepared according to the method described in [16]. The diagram of the setup for synthesis is given in Fig. 1. The setup works as follows. A high-voltage pulse voltage is applied to the electrodes from the generator, and the plasma appears between the electrodes.

The end face of the PTFE rod is placed in this air plasma, after which blue plasma is formed in the placement area. Then, the end face of another PTFE rod is introduced into this plasma, after which both rods begin to burn with a red flame with the release of thick black smoke, consisting of fibrous formations. The smoke-like product was deposited on a fluoroplastic substrate in the form of a powder, which was collected from the substrate for research. Part of the powder was annealed in air or in an argon atmosphere. 
Kuryavyi et al., Adv. Nan. Res.; Vol. 4, Issue 1, pp: 10-26, 2021

The composition and structure of the initial and annealed samples were studied by various physical methods.

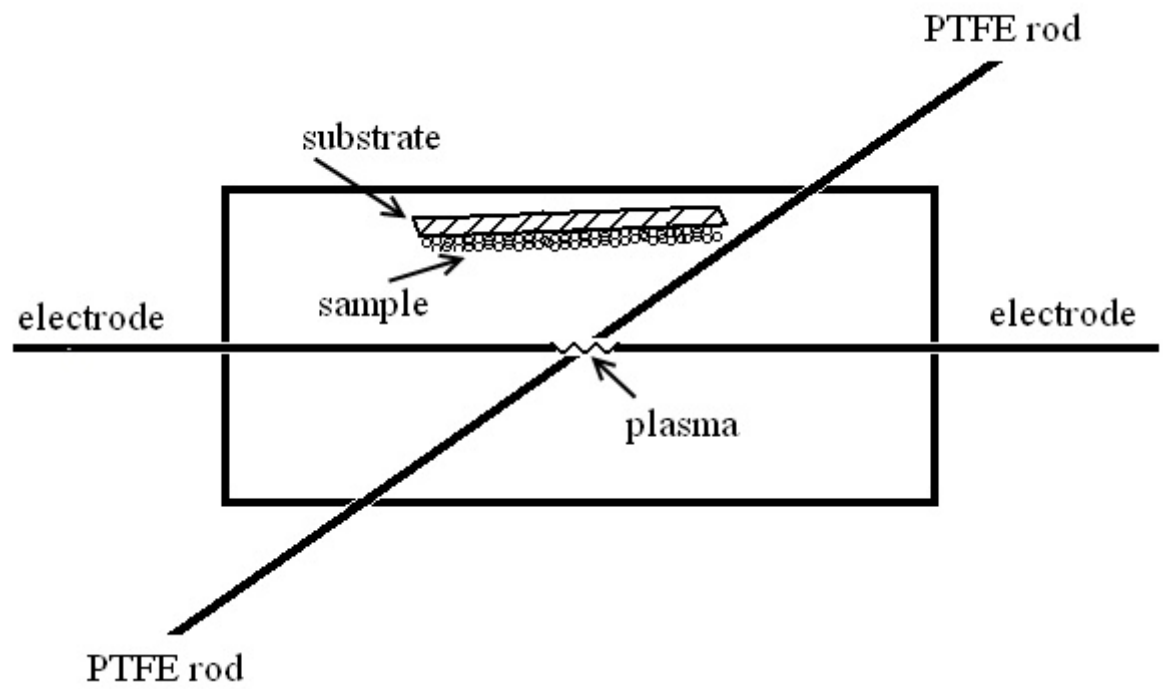

Figure 1: Scheme of synthesis of nanocomposites

The morphology of the samples was studied using a Hitachi S5500 scanning electron microscope (SEM) (Japan) and an attachment to this microscope for scanning transmission electron microscopy (STEM). The local elemental composition of the specimens was determined using energy-dispersive spectroscopy (EDS) on Thermo Scientific spectrometer (United States) mounted as an adapter on the Hitachi S5500 microscope. The XRD studies were carried out with a RIGAKU Smart Lab diffractometer using a 9kW rotating anode, $\mathrm{CuK} \alpha$ radiation (Ni-filter), Bragg-Brentano geometry, a silicon zero-background specimen holder and a HyPix-3000 detector operating in the 1D measurement mode were used. The diffraction patterns were recorded within the $2 \theta$ range of $5^{\circ} \div 90^{\circ}$, at the $2 \theta$ step of $0.01^{\circ}$. The XRD peaks were identified using the database ICDD PDF-2. The magnetic characteristics of the specimens were measured on an MPMS-XL-5 SQUID magnetometer (Quantum Design, United States). X-ray electron spectroscopy (XES) was carried out using a surface analysis complex of SPECS Company (Bruker, Germany). 19F NMR spectra were recorded on a Bruker Avance AV-300 solid-state NMR spectrometer (the field is 7.04 T). Magic-angle spinning (MAS) of the specimen with the frequencies of $12-16 \mathrm{kHz}$ and $\mathrm{Hahn}$ spin echo were used. Chemical shifts of the signals were calculated from $\mathrm{CFCl}_{3}$. The measurement error of chemical shift was 1 ppm. Raman spectroscopy was recorded on a WiTec alpha500 Raman microscope (Germany) with the laser wavelength of $535.5 \mathrm{~nm}$. Infrared spectroscopy was recorded on an EQUINOX 55/S IR Fourier spectrometer (Bruker, Germany).

\section{Results and Discussion}

In this work, four types of samples were obtained and studied. The initial sample, hereinafter sample 1, was obtained in the plasma of the pulsed high-voltage discharge using nickel electrodes and fluoroplastic according to the above procedure. The other three types of samples were obtained by annealing sample 1 . Sample 2 was obtained by annealing sample 1 in air at a temperature of $773 \mathrm{~K}$ for 1 hour. Sample 3 was obtained by annealing sample 1 in air at a temperature of $1173 \mathrm{~K}$ for 1 hour. Sample 4 was obtained by annealing sample 1 in an argon atmosphere at a temperature of $1073 \mathrm{~K}$ for 1 hour. 
Nanocomposite Obtained in the Plasma of a Pulsed High Voltage Discharge Using Nickel Electrodes and PTFE

\subsection{Sample 1 obtained in the plasma of the pulsed high-voltage discharge using nickel electrodes}

According to the data of scanning electron microscopy, sample 1 consists of branched and intertwined

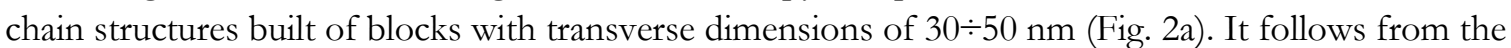
STEM data that denser nanoparticles near $5 \div 8 \mathrm{~nm}$ in size are incorporated in the blocks (Fig. 2b).
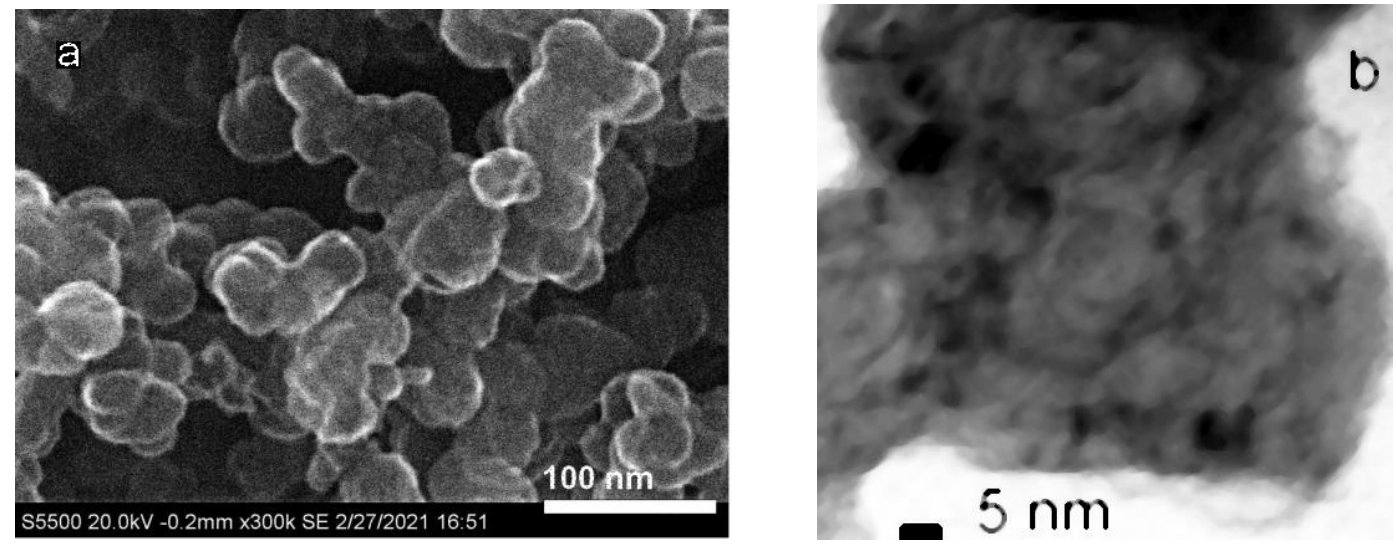

Figure 2: SEM (a) and STEM (b) of sample 1

The elemental composition of specimen 1 at various points was studied using local energy-dispersive spectroscopy. According to the results of ten measurements at various points of different nanofibrils, they contain $74.1 \div 76.8$ at $\%$ C, $22.9 \div 25.9$ at $\% \mathrm{~F}, 1.1 \div 4.4$ at $\%$ O, and $0.1 \div 0.45$ at $\%$ of Ni.

The XPA diffraction pattern of specimen 1 is given in Fig. 3. The diffraction pattern of specimen 1 contains one crystalline peak at $2 \Theta=18^{\circ}$ and a diffused halo in the range of $2 \Theta=40^{\circ} \div 50^{\circ}$ as in PTFE [27], while other crystal peaks from PTFE are not detected presumably because of their low intensity against the noise background. In addition, there is a halo in the range of $2 \Theta=20^{\circ} \div 30^{\circ}$ on the diffraction pattern of specimen 1 , which is not observed in PTFE. This halo can be caused by the carbon component in the specimen, which exists in the disordered phase [28]. In addition, the diffraction pattern contains a set of low-intensity crystalline peaks corresponding to the $\mathrm{NiF}_{2}$ spectrum (see inset Fig. 3).

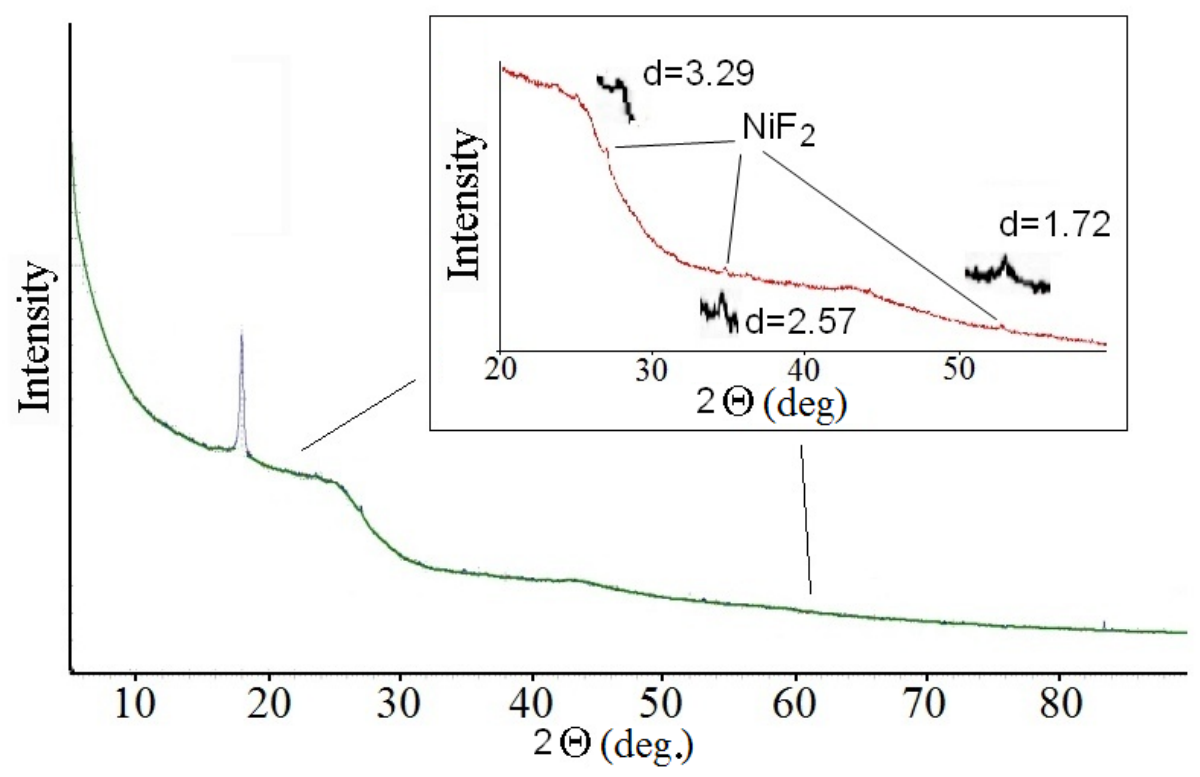

Figure 3: XPA spectrum of sample 1, the inset shows an enlarged fragment of the spectrum and on it the peaks corresponding to $\mathrm{NiF}_{2}$ are marked. 
Kuryavyi et al., Adv. Nan. Res.; Vol. 4, Issue 1, pp: 10-26, 2021

The ESR spectrum of sample 1 (Fig. 4) contains a wide peak with the width of 415 Oe and $g=2.26$, typical of the ESR spectrum of divalent nickel [29]. These data agree with the XRD data on the presence of $\mathrm{NiF}_{2}$ in the sample. In addition, the ESR spectrum of sample 1 contains a narrow symmetric peak with a width of 14 Oe and $g \approx 2.005$. The width, symmetry, and position of this peak make it possible to assign it to the EPR spectrum of carbon radicals [30].

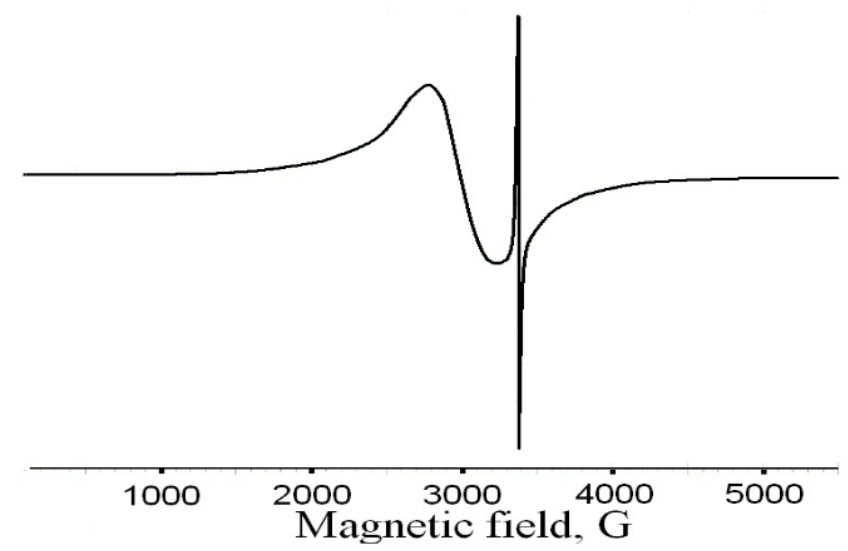

Figure 4: ESR spectrum of sample 1. $v=9478 \mathrm{MHz}$.

In XES spectra of specimen 1, there are the bands corresponding to the C, F, O, and Ni elements (Fig. 5). The band of carbon is split into components, which correspond to the presence of its chemical bonds with fluorine in $-\mathrm{CF}_{3},-\mathrm{CF}_{2}$, and $-\mathrm{CF}$ fragments, as well as to presence $-\mathrm{C}-\mathrm{C}-$ bond and $-\mathrm{C}=\mathrm{C}-$ bond of aliphatic carbon [31] (Fig. 5, Table 1). The fragments of $-\mathrm{CF}_{3}$ and $-\mathrm{CF}_{2}$ correspond to the presence of PTFE molecules in the specimen, which agrees with XPA data. Two peaks correspond to fluorinated carbon of -CF type. This implies that single fluorinated carbon is present in specimen 1 as part of different molecular fragments. The band of nickel has low intensity, which corresponds to the nickel content in the surface layer of the specimen of about 0.1 at $\%$. This value is less than the nickel content determined by the EDS method (up to 0.45 at \%). This divergence can be rationalized by the known low penetration depth of XES analysis, less than $10 \mathrm{~nm}$, and by inclusion of nickel-containing nanoparticles in the bulk of specimen. The bond energy of nickel corresponds to the chemical bond nickel with fluorine.

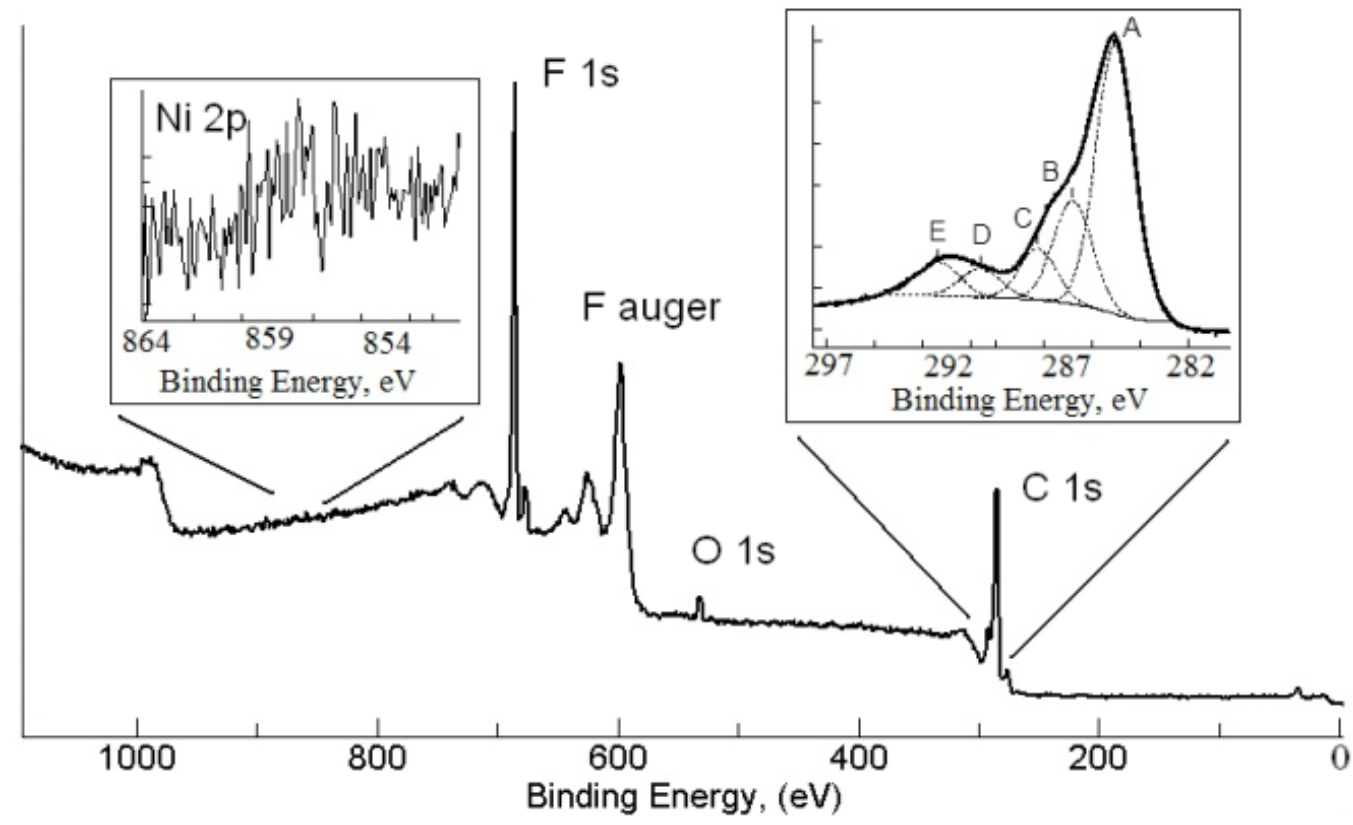

Figure 5: XES spectra of sample 1. 
Nanocomposite Obtained in the Plasma of a Pulsed High Voltage Discharge Using Nickel Electrodes and PTFE

Table 1: Bond energies $E_{\text {bond }}(\mathrm{eV})$ and relative contents (at.\%) of elements in specimen 1

\begin{tabular}{|l|c|c|c|c|c|c|c|c|c|}
\hline $\begin{array}{l}\text { Type of } \\
\text { framework } \\
\text { electrons }\end{array}$ & Ni (2p) & F (1s) & \multicolumn{2}{|c|}{ O (1s) } & \multicolumn{5}{|c|}{ C (1s) } \\
\hline at.\% & 0.1 & 33 & \multicolumn{2}{|c|}{2.7} & \multicolumn{5}{|c|}{0} \\
\hline $\mathrm{E}_{\text {bond }}(\mathrm{eV})$ & 856.0 & 686.1 & 538.8 & 531.0 & 292.4 & 290.6 & 288.2 & 286.7 & 285 \\
\hline at. $\%$ & 0.1 & 33 & 1.3 & 1.4 & 7.7 & 6.3 & 10.1 & 19 & 21.1 \\
\hline $\begin{array}{l}\text { Type of } \\
\text { bond }\end{array}$ & Ni-F & & & & $-\mathrm{CF}_{3}$ & $-\mathrm{CF}_{2^{-}}$ & & $-\mathrm{CF}-$ & $\begin{array}{l}\text {-CC- } \\
\text {-C=C- }\end{array}$ \\
\hline
\end{tabular}

The IR spectrum of specimen 1 (Fig. 6a) indicates broad band in the range of $1100 \div 1500 \mathrm{~cm}^{-1}$, where frequency of stretching vibrations of $\mathrm{C}-\mathrm{C}$ and $\mathrm{C}-\mathrm{O}$ bonds in aliphatic carbon, as well stretching vibrations of $\mathrm{C}-\mathrm{F}$ bonds in fluorinated forms of carbon, may be located [32].

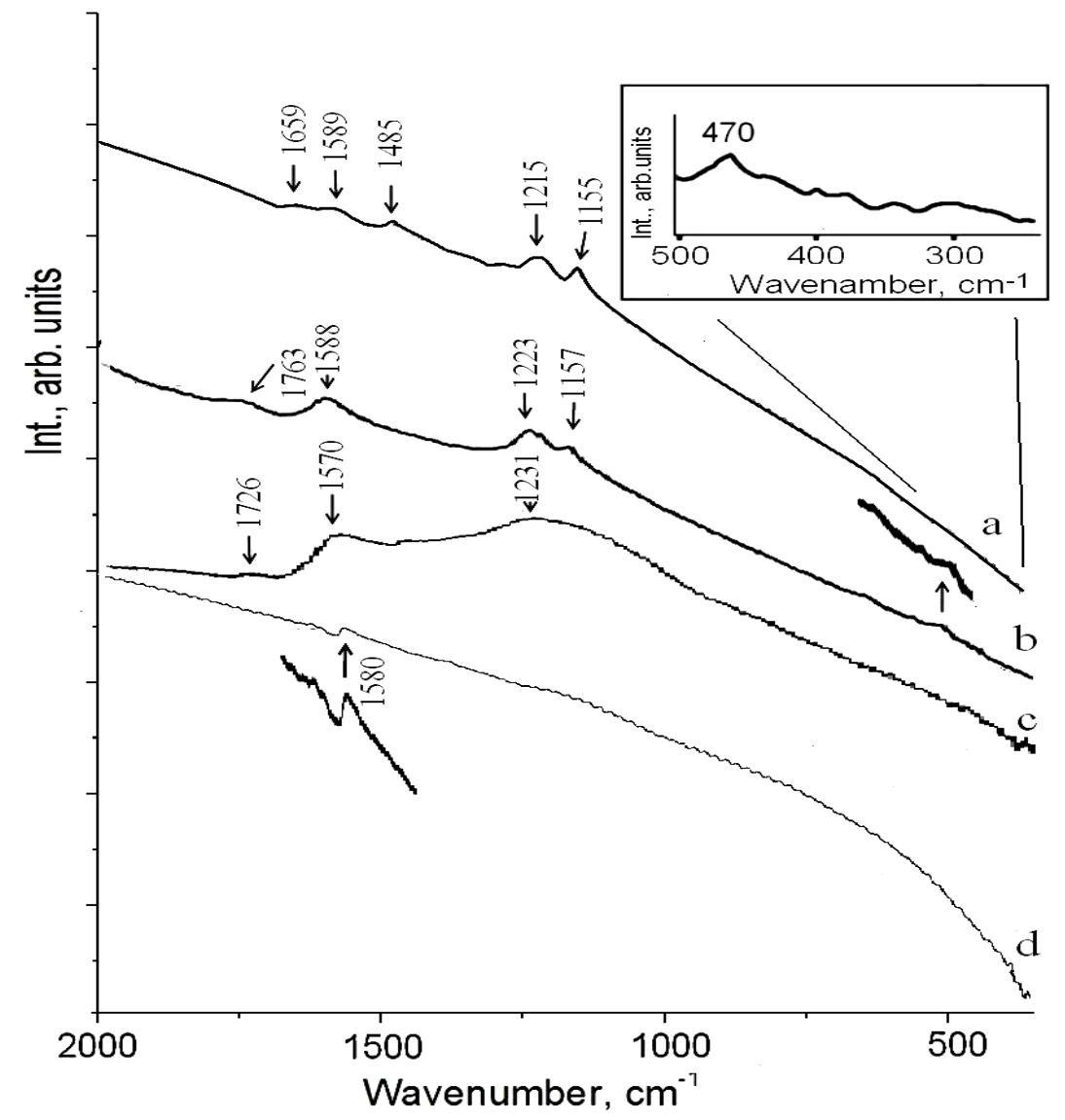

Figure 6: IR spectra of samples: a - spectrum of sample 1; $b$ - spectrum of sample 2; $c$ - spectrum of sample 4; $d$-spectrum of a graphite electrode. The inset shows the low-frequency part of the spectrum of sample 1, that recorded separately in the low-frequency range of the spectrometer.

Individual peaks at $1217 \mathrm{~cm}^{-1}$ and $1154 \mathrm{~cm}^{-1}$ are recorded in the same range, which are intrinsic to the stretching vibrations of $\mathrm{CF}_{2}$ groups in PTFE [33]. The spectrum contains the peak with a maximum at 1589 $\mathrm{cm}^{-1}$ corresponding to vibrations of double bonds of hexagonal groups in the plane of atomic layers of graphite [34]. This data shows the presence of either graphene or graphite components in specimen 1. An example of the IR control spectrum of graphite electrode containing the similar peak $\left(1580 \mathrm{~cm}^{-1}\right)$ recorded in this work is shown in Fig. 6 d. The less intense band located in the spectrum at $1659 \mathrm{~cm}^{-1}$ refers to the vibrations of water molecules adsorbed by the $\mathrm{KBr}$ matrix or by the sample itself. The low-frequency part 
Kuryavyi et al., Adv. Nan. Res.; Vol. 4, Issue 1, pp: 10-26, 2021

of the spectrum was recorded separately, which is shown in the inset in Fig. 6. The spectrum contains a band at $470 \mathrm{~cm}^{-1}$, which is in the range of stretching vibrations of metal fluorides and can be attributed to $\mathrm{NiF}_{2}$.

According to NMR data, the spectrum of sample 1 (Fig. 7) contains: the peak with $-124.6 \mathrm{ppm}$ which corresponds to fragments of $\mathrm{CF}_{2}$ of PTFE macromolecules [35]. The spectrum contains an unresolved halo with weak signals at $-139.3 \mathrm{ppm}$ at $-156.9 \mathrm{ppm}$. The signal at $-139.3 \mathrm{ppm}$ can be attributed to the fluorine in the composition of $\mathrm{CF}_{2}$ groups located near the ends of the polymer chain of PTFE. The signal at - 156.9 $\mathrm{ppm}$ can be attributed to fluorine in the $-\mathrm{CF}-\mathrm{CF}-$ or $-\mathrm{CF}=\mathrm{CF}-$ groups of amorphous fluorinated carbon [35]. In addition, the spectrum contains a signal of $61 \mathrm{ppm}$, which, according to the literature, can be attributed to fluorine, which is a member of the groups $\mathrm{F}_{3} \mathrm{C}>\mathrm{C}=\mathrm{C}<[35]$ or $-\mathrm{CF}=\mathrm{C}<\mathrm{F}_{\mathrm{F}}$ [36]. From the obtained NMR data, it is realistic to assume that during the destruction of PTFE in the plasma in different places of the PTFE molecules all fluorine atoms are detached from the carbon atom and double bonds are formed between the carbon atoms that have lost fluorine.

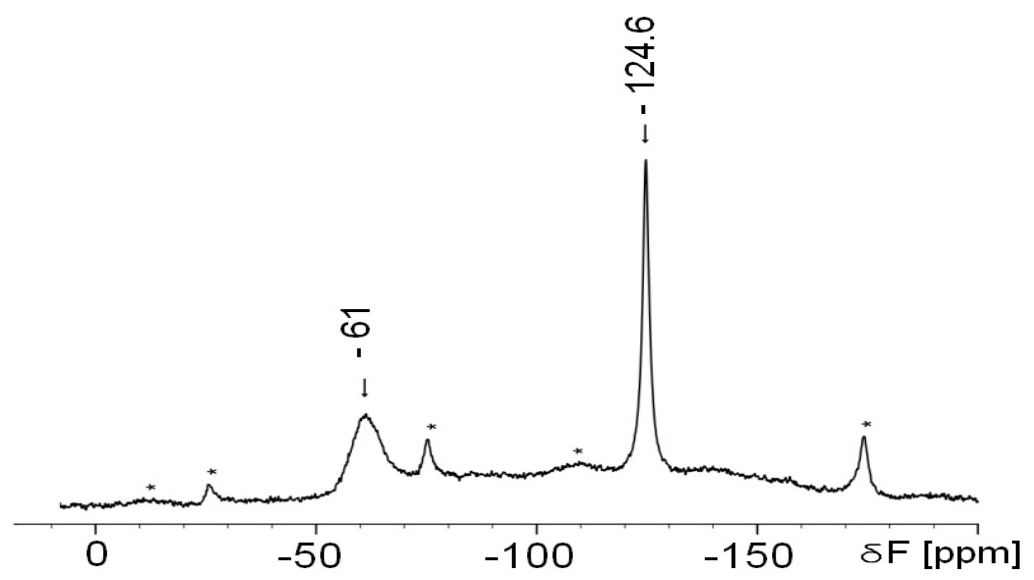

Figure 7: NMR spectrum of sample 1. The * marks the lateral lines from the rotation of the sample.

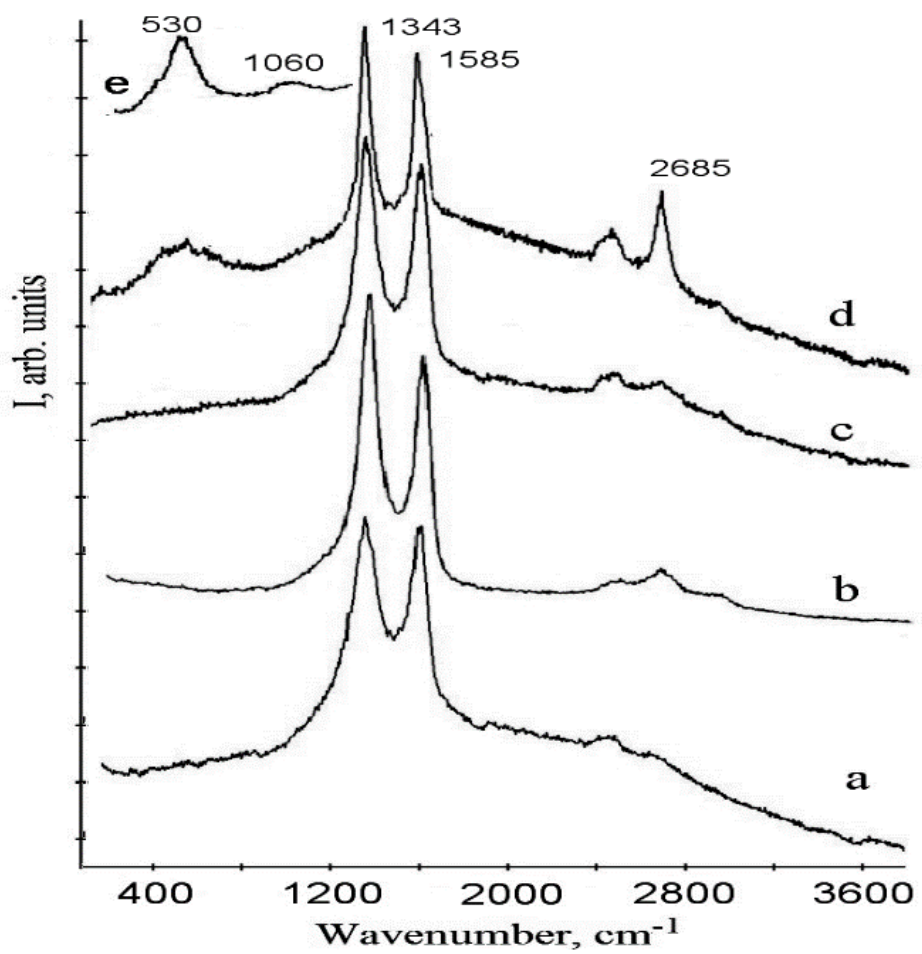

Figure 8: Raman spectra of samples: $a$ - spectrum of sample 1; $b$ - spectrum of sample 4; $c, d$ - spectra recorded in different regions of sample 2; e - spectrum of sample 3. 
Nanocomposite Obtained in the Plasma of a Pulsed High Voltage Discharge Using Nickel Electrodes and PTFE

The Raman spectrum of specimen 1 (Fig. 8a) includes the characteristic D (the peak at $1343 \mathrm{~cm}^{-1}$ ) and G (the peak at $1585 \mathrm{~cm}^{-1}$ ) lines of carbon materials, which correspond to the presence in materials of nanosized disordered graphite-like structures [37]. In the range of $2000 \div 3000 \mathrm{~cm}^{-1}$ are located overtone of these signals (peaks 2D $\left(2463 \mathrm{~cm}^{-1}\right)$ and $\left.\mathrm{G}+\mathrm{D}\left(2683 \mathrm{~cm}^{-1}\right)\right)$. It is known that the presence of the $\mathrm{D}$ peak in spectra indicates disordering in structure of graphite, which is related to the presence of defects [37]; the broader the peak, the larger the disordering. The $G$ peak corresponds to the stretching vibrations of $\mathrm{sp}^{2}$ bonds in the plane of the defect less graphite. Thus, Raman data show that there are graphitized regions in specimen 1 with structural disordering. The sizes of the graphitized regions were estimated from the ratio of the intensities of the peaks $G$ and $D$ according to the formula of $F$. Tuinstra and J. Koening [38] L $\approx 4.4$ $\left(\mathrm{I}_{\mathrm{G}} / \mathrm{I}_{\mathrm{D}}\right)$ and equal to about $4.1 \mathrm{~nm}$. It should be noted that there are no lines from PTFE in the Raman spectrum of specimen1 [16] (Fig. 8a), while the XPA and IR data indicate the incorporation of PTFE in the specimen. This may be due to the low content of PTFE and the screening factor of laser radiation by the carbon material of the sample. Also, the Raman spectrum of the sample does not contain signals from nickel fluoride, possibly for the same reasons.

\subsubsection{Discussion of the structure and composition of sample 1}

Consideration of the above data gives the following generalization. Specimen 1 morphologically represents chain formations built from blocks with sizes of $30 \div 50 \mathrm{~nm}$. The elemental composition of blocks consists of $\mathrm{C}, \mathrm{F}, \mathrm{O}$, and $\mathrm{Ni}$ according to XPA, ESR, EDS and XES data. The carbon content is up to 74 at \%, fluorine content is up to 22 at $\% \mathrm{~F}$ in the blocks, while that of nickel is up to 0.45 at $\%$ and the rest is oxygen according to EDS data. Blocks contain PTFE according to XPA and IR data; there are molecular fragments of $-\mathrm{CF}$ according to NMR, IR, and XES data; there are possible molecular fragments $-\mathrm{CF}=$ $\mathrm{CF}-,{ }_{3} \mathrm{C}>\mathrm{C}=\mathrm{C}<$ and $-\mathrm{CF}=\mathrm{C}<\mathrm{F}_{\mathrm{F}}$ according to NMR data; there is aliphatic carbon according to XES, IR data; there is graphite according to IR data. Blocks contain nanosized graphitized regions according to Rama data. The size of the graphitized regions is about $4.1 \mathrm{~nm}$. As follows from XPA, EDS, ESR and XES data nickel is involved in the elemental composition of specimen 1. According to XPA, XES, and IR data, sample 1 contains nickel in the composition of $\mathrm{NiF}_{2}$. It is known that the particles containing metal compounds are transmitted worse than the particles containing carbon material without metals on transmission electron microscope. Thus, it may be concluded that nanoparticles near $5 \div 8 \mathrm{~nm}$ in size included in the blocks of branched and intertwined chain structures (Fig. 2b) are $\mathrm{NiF}_{2}$ particles.

\subsubsection{Magnetic properties of the sample 1}

According to the data obtained, sample 1 contains nano-sized particles of $\mathrm{NiF}_{2}$ and nano-sized graphitelike regions. In both cases, specific features of the magnetic properties associated with the nanosize of these objects are expected [39, 40]. In this connection, the temperature and field dependences of the magnetic susceptibility of sample 1 were investigated. The temperature dependences of the magnetic susceptibility $(\mathrm{M}(\mathrm{T})$ ) were measured in the known FC and ZFC modes. FC corresponds to the temperature dependence of the magnetic susceptibility measured after cooling in nonzero magnetic field ( $\mathrm{H}=200$ Oe in the considered case), ZFC corresponds to $\mathrm{M}(\mathrm{T})$ measure after cooling without applying the magnetic field. The resulting dependences FC and ZFC are shown in Fig. 9a. 
Kuryavyi et al., Adv. Nan. Res.; Vol. 4, Issue 1, pp: 10-26, 2021

a

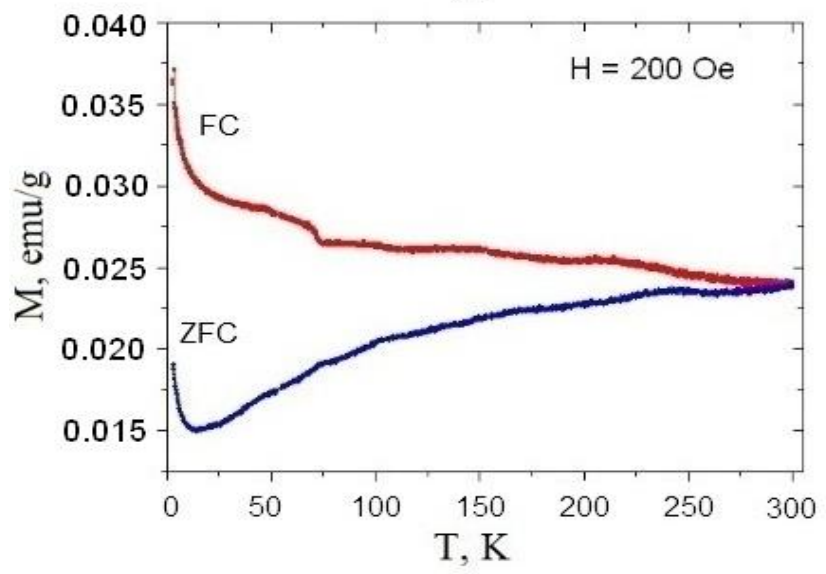

C

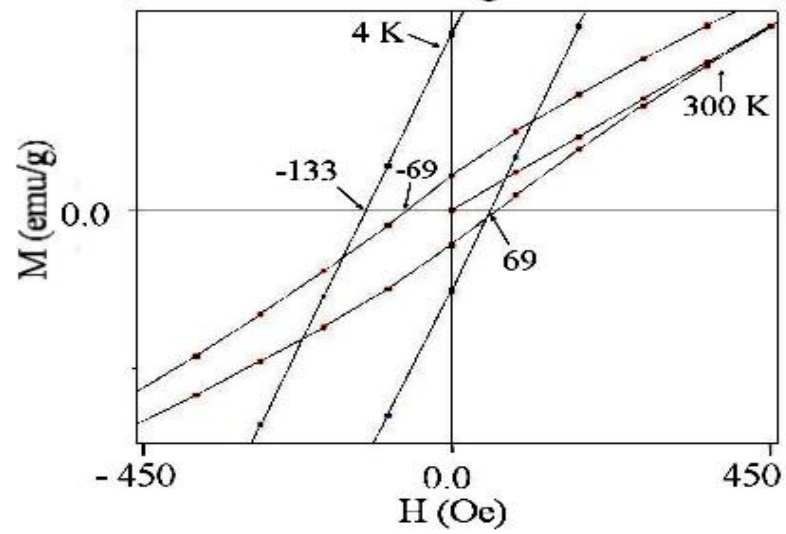

b
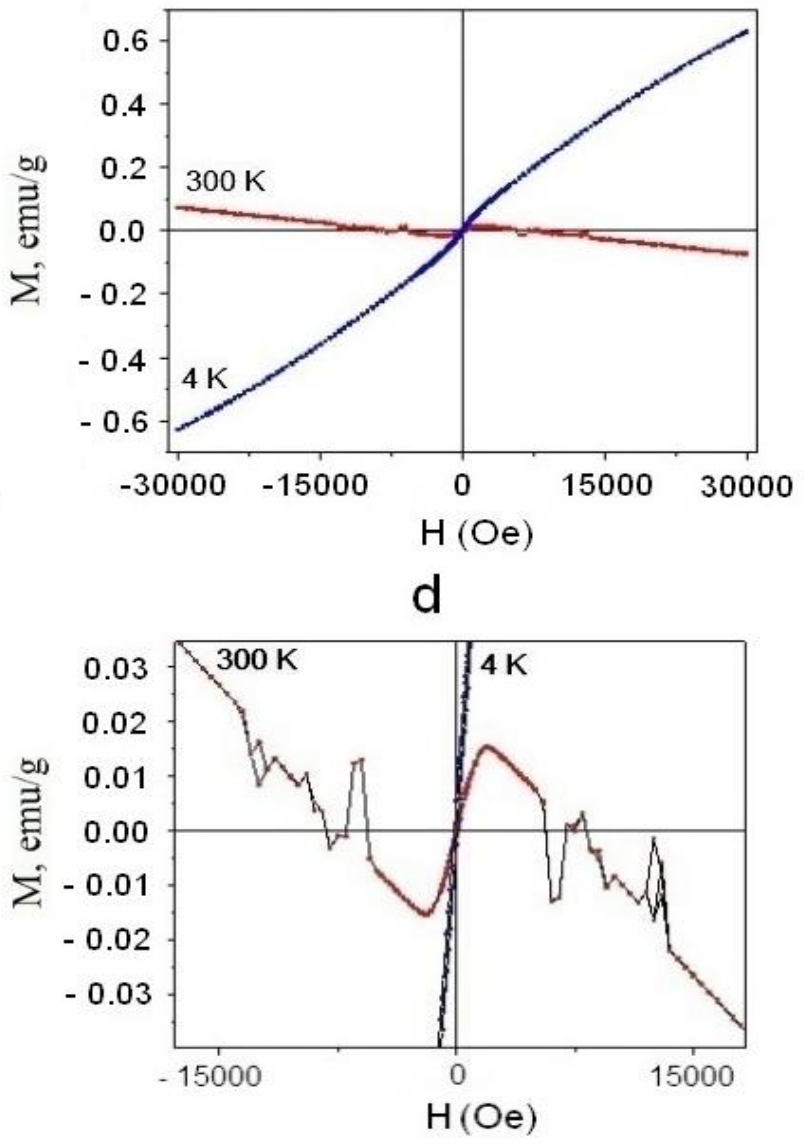

Figure 9: Temperature and field dependences of the magnetic susceptibility of the sample 1

In the entire studied temperature range, there is divergence of the FC and ZFC curves, the temperature hysteresis. The appearance of hysteresis can be caused by a number of factors: the existence of a spin glass state (below the merging temperature of the FC and ZFC curves) [41]; states with blocking of the magnetic moment of nanoparticles (below the merging temperature of the FC and ZFC curves) [42]; the state of a super spin glass (micro spin glass) [43], and in the general case - the presence of a metastable state which is formed in the external magnetic field during the interaction of magnetic moments. In the considered case of sample 1, the divergence of the FC and ZFC curves manifests itself in the entire range of the studied temperatures from $4 \mathrm{~K}$ to $300 \mathrm{~K}$. It can be assumed that states with blocking of the magnetic moment of nanoparticles or the state of a spin glass are realized in this entire range. There is evidence that the second option is more realistic, since the sizes of $\mathrm{NiF}_{2}$ nanoparticles are small (less than $8 \mathrm{~nm}$ ) and, at such sizes, the transition to the state of blocking of the magnetic moment of such particles is expected at temperatures much lower than $300 \mathrm{~K}$. The transition to blocking of the magnetic moment is reflected in the manifestation of a peak in the ZFC curve at temperature of this transition [44], which in Fig. 9a is missing. However, to find out the true reason for the divergence between the FC and ZFC curves in sample 1, additional experiments are required. The FC dependence shows a smooth stepwise change at $\mathrm{T}=73.5 \pm 0.5 \mathrm{~K}$. This temperature value, well coincides with the temperature $\mathrm{T}_{\mathrm{N}}=73.2 \mathrm{~K}$ of the transition of bulk crystals $\mathrm{NiF}_{2}$ to the antiferromagnetic phase [45].

The $(\mathrm{M}(\mathrm{H})$ ) dependences for samples 1 and 2 were recorded at $\mathrm{T}=300 \mathrm{~K}$ and $\mathrm{T}=4 \mathrm{~K}$ (Fig. 9b, Fig. 9c, Fig. 9d). At $\mathrm{T}=4 \mathrm{~K}$, the dependence $\mathrm{M}(\mathrm{H})$ contains a magnetic hysteresis loop shifted to negative fields, $\mathrm{M}(\mathrm{H})$ does not reach saturation at all values of the applied field up to $30000 \mathrm{Oe}-\mathrm{Fig}$. 9c, Fig. 9 b. This form of $\mathrm{M}(\mathrm{H})$ corresponds to the case of an antiferromagnetic phase with superposition of a magnetic hysteresis loop from the ferromagnetic phase. The shift of the magnetic hysteresis loop means the presence of an exchange bias interaction between AFM and FM phases in the sample [46]. AFM / FM interaction 
Nanocomposite Obtained in the Plasma of a Pulsed High Voltage Discharge Using Nickel Electrodes and PTFE

can be realized in nanoparticles of antiferromagnetic materials in the presence of uncompensated spins on the surface of these particles, which, upon magnetic interaction with each other, form the FM phase. In the case of sample 1, the AFM / FM interaction is expected in $\mathrm{NiF}_{2}$ nanoparticles at $\mathrm{T}<73.2 \mathrm{~K}$, since nickel fluoride at $\mathrm{T}=73.2 \mathrm{~K}$ undergoes a transition to the antiferromagnetic phase.

Due to edge effects, graphite nanoparticles, like $\mathrm{NiF}_{2}$ nanoparticles, can acquire ferromagnetic properties that are not inherent in macroscopic analogs [47]. Therefore, the ferromagnetic contribution to the field dependence $\mathrm{M}(\mathrm{H})$ of sample 1 from graphite nanoparticles is possible. Further experimentation is required to resolve this issue.

At $\mathrm{T}=300 \mathrm{~K}$, the general form of the $\mathrm{M}(\mathrm{H})$ dependence corresponds to the presence of diamagnetic and ferromagnetic phases in sample 1 (Fig. 9b, Fig. 9c, Fig. 9d). The diamagnetic phase manifests itself in the presence of a negative linear dependence $\mathrm{M}(\mathrm{H})$ (Fig. 9b), the ferromagnetic component manifests itself in the presence of a magnetic hysteresis loop (Fig. 9c). It is realistic to believe that in sample 1, its carbon component exhibits diamagnetic properties, since diamagnetism is inherent in carbon materials [48].

At $\mathrm{T}=300 \mathrm{~K}$, no shift of the magnetic hysteresis loop is observed (Fig. 9c). It can be assumed that the ferromagnetic component is associated with the interaction of uncompensated spins on the surface of $\mathrm{NiF}_{2}$ nanoparticles. In this case, the substance of the particle core is in a paramagnetic state, since $\mathrm{T}=300 \mathrm{~K}$ is higher than the Néel temperature. Under these conditions, there is no AFM / FM interaction between the core and the shell of particles and, accordingly, no shift of the magnetic hysteresis loop is observed.

At $\mathrm{T}=300 \mathrm{~K}$, against the background of the linear "diamagnetic" component of the $\mathrm{M}(\mathrm{H})$ curve, abrupt changes in $\mathrm{M}(\mathrm{H})$ are observed, located anti-symmetrically relative to the $\mathrm{M}$ axis (Fig. 9d). This type of dependence was observed by us earlier for nanocomposites obtained using copper electrodes [16]. These composites, like sample 1, contain nano-sized graphite-like regions. In [16], it was assumed that the abrupt changes in $\mathrm{M}(\mathrm{H})$ can be explained by the existence of Josephson contacts in the sample, which can be represented by graphite-like granules placed in a matrix of amorphous carbon [49, 50]. The same explanation can be applied to sample 1. However, another explanation can be offered. As is known, uncompensated spins exist at the edges of nanosized graphite regions [47], which can be in exchange interaction and form an analogue of the AFM state of these regions. According to Raman data, sample 1 contains nanosized graphite-like regions. Therefore, it can be assumed that the jumps on $M(H)$ are associated with the reorientation of spins located at the edges of these regions and reflect transitions similar to the known magnetic phase flip-flop transitions in antiferromagnetic materials [51, 52]. To clarification the real nature of the observed jumps in $\mathrm{M}(\mathrm{H})$, separate additional experiments are required.

\subsection{Samples obtained by annealing sample 1 under various conditions}

Sample 1 was annealed at different temperatures in air and in argon. The structure and composition of the samples obtained as a result of annealing have been studied.

\subsubsection{Sample 2, obtained by annealing sample 1 in air for 1 hour at $773 \mathrm{~K}$}

The diffractogram of sample 2 is shown in Fig. 10. It contains crystalline peaks related to PTFE [27] and a set of low intensity crystalline peaks corresponding to the spectrum of $\mathrm{NiF}_{2}$. Also, the diffractogram of sample 1 has a halo in the region $2 \theta=20 \div 30^{\circ}$, which is characteristic of carbon materials in a state of a disordered phase [28]. In addition, the diffraction pattern contains a peak with $\mathrm{d}=3.425$ and a low-intensity halo located in the region $2 \theta=41 \div 45^{\circ}$, which can correspond to the spectrum of low-layer graphene [53, 54]. 


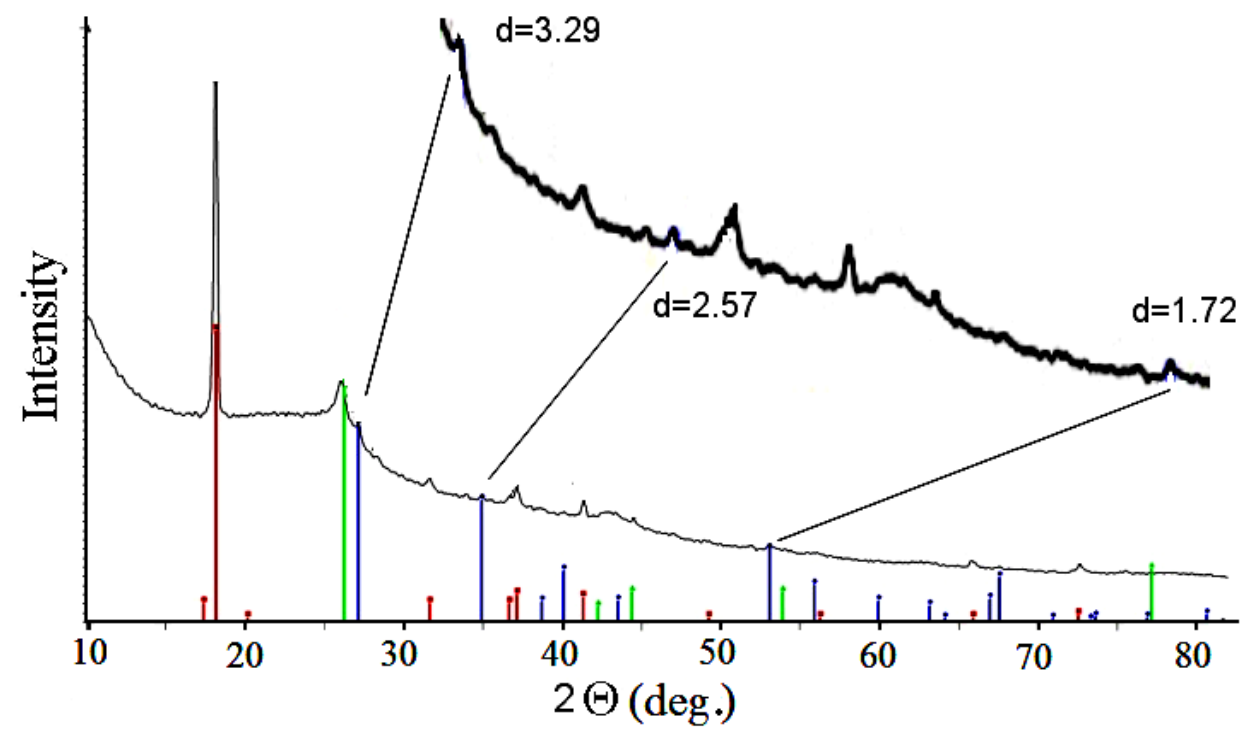

Figure 10: XPA spectrum of sample 2, the inset shows an enlarged fragment of the diffractogram, where the peaks corresponding to NiF2 are indicated.
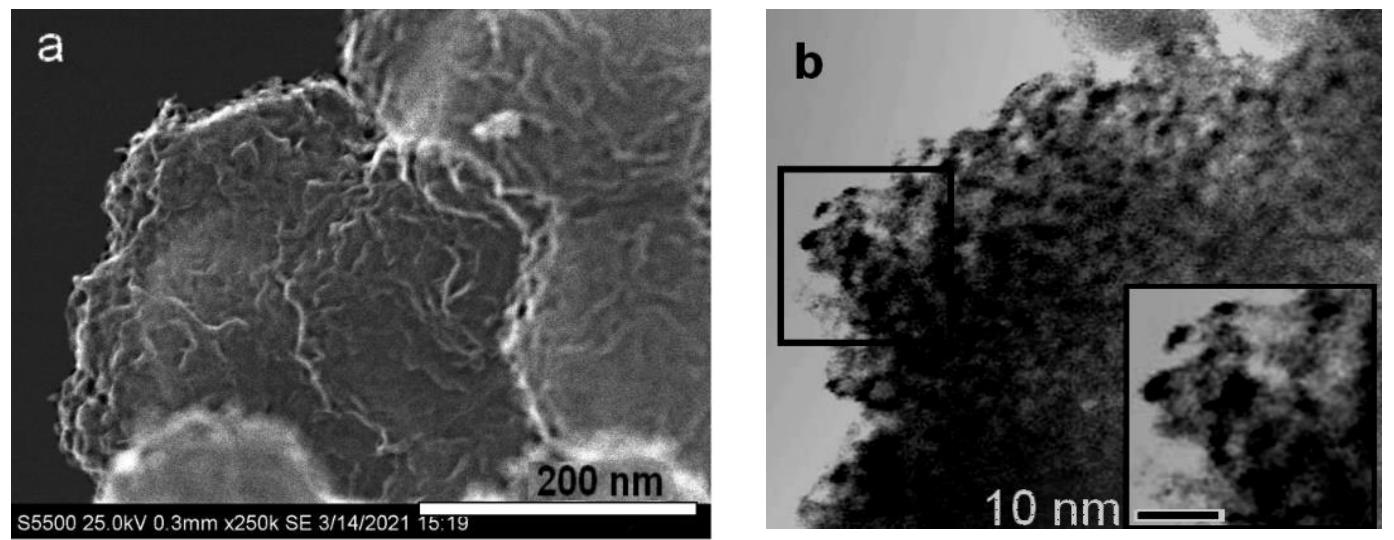

Figure 11: SEM (a) and STEM (b) of sample 2

In fig. 11 shows the SEM and STEM images of sample 2. It follows from the SEM data that in sample 2, as well as in sample 1, there are nano-sized blocks, but unlike the blocks of sample 1, they have larger sizes (up to $300 \mathrm{~nm}$ ) and have a layered structure (Fig. 11a). According to the STEM data, nanoparticles near 5 $\mathrm{nm}$ in size are embedded in the material of the blocks (Fig. 11b). Based on the XPA data, it is realistic to assume that these nanoparticles contain $\mathrm{NiF}_{2}$.

The Raman spectra of sample 2 recorded at different points are different (Fig.8c, Fig.8d). In some places, they are similar to the Raman spectra of sample 1, and correspond to the spectrum of graphitized regions with structural disordering - Fig. 8 c. The sizes of graphitized regions, estimated by the formula of F. Tuinstra and J. Koening, are equal to $\sim 3.5 \mathrm{~nm}$. Elsewhere, the Raman spectrum contains an intense peak with a maximum at $2685 \mathrm{~cm}^{-1}$ (Fig. 8d), which indicates the presence of graphene regions in the sample [55]. In addition, in the spectrum shown in Fig. $8 \mathrm{~d}$, a broad peak is seen with a maximum at $537 \mathrm{~cm}^{-1}$, which can be attributed to the Raman signal from nickel oxide. In the XPA spectrum, peaks from nickel oxide are not observed, possibly due to the fact that $\mathrm{NiO}$ enters sample 2 in an amorphous form or its content in the sample is very small. The most probable place for the formation of $\mathrm{NiO}$ upon annealing of sample 1 is the surface of $\mathrm{NiF}_{2}$ nanoparticles. It is realistic to assume that $\mathrm{NiO}$ is formed on the surface of $\mathrm{NiF}_{2}$ nanoparticles in the form of a shell. 
Nanocomposite Obtained in the Plasma of a Pulsed High Voltage Discharge Using Nickel Electrodes and PTFE

The IR spectrum of sample 2 (Fig. 6b), like the spectrum of sample 1, contains peaks that are characteristic of stretching vibrations of $\mathrm{CF}_{2}$ groups in PTFE [33], at $1223 \mathrm{~cm}^{-1}$ and $1157 \mathrm{~cm}^{-1}$. The spectrum contains the peak at $1588 \mathrm{~cm}^{-1}$ corresponding to vibrations of double bonds of hexagonal groups in the plane of atomic layers of graphite [34]. In addition, the spectrum contains the band with maximum at $1763 \mathrm{~cm}^{-1}$ located in the range of bond vibration frequencies $-\mathrm{CF}=\mathrm{CF}-\left(1730,1717 \mathrm{~cm}^{-1}\right)$ and $-\mathrm{CF}=\mathrm{CF}_{2}(1785$ $\mathrm{cm}^{-1}$. These bonds arises when bonds are broken in PTFE molecules [16]. In the low-frequency region of the spectrum, low-intensity peaks are observed at $620 \mathrm{~cm}^{-1}, 539 \mathrm{~cm}^{-1}, 490 \mathrm{~cm}^{-1}$, which characterize the supramolecular structures of PTFE [33,34]. It should be noted that, in comparison with the spectrum of sample 1, in the IR spectrum of sample 2 there is no band in the range $1200-1500 \mathrm{~cm}^{-1}$, in which the frequencies of stretching vibrations of $\mathrm{C}-\mathrm{C}$ and $\mathrm{C}-\mathrm{O}$ bonds in aliphatic carbon, as well as $\mathrm{C}-\mathrm{F}$ bonds in fluorinated forms of carbon [32] are expected. Its absence in sample 2 indicates the high proportion of graphitization of amorphous carbon from the composition of sample 1, which occurs during its annealing. From consideration of the data obtained, it follows that when sample 1 is annealed in air for an 1 hour at $773 \mathrm{~K}$, graphitization of the carbon material occurs, the annealed sample still contains PTFE, some of the PTFE molecules of the initial sample undergo ruptures, after which bonds are formed - CF $=\mathrm{CF}$ - and (or) - $\mathrm{CF}=\mathrm{CF}_{2}$. The carbon portion of sample 2 contains nanoscale disordered graphite-like structures and nanoscale graphene regions. In these structures, particles are scattered that contain $\mathrm{NF}_{2}$ and $\mathrm{NiO}$. The sizes of nanoparticles are near $5 \mathrm{~nm}$.

\subsubsection{Sample 3, obtained by annealing sample 1 in air for 1 hour at $1173 \mathrm{~K}$}

Sample 3 was obtained in small quantities. This is due to the fact that the carbon and fluorocarbon components of the sample, which make up most of it, pass into a gaseous state when heated to $1173 \mathrm{~K}$. In fact, we obtained a film on the surface of a platinum crucible, in which annealing was performed. Sample 3 was studied by SEM, STEM, and Raman scattering methods. According to the SEM and STEM data, the sample is composed of nanoparticles near $5 \mathrm{~nm}$ in size (Fig. 12 a, Fig. 12b).
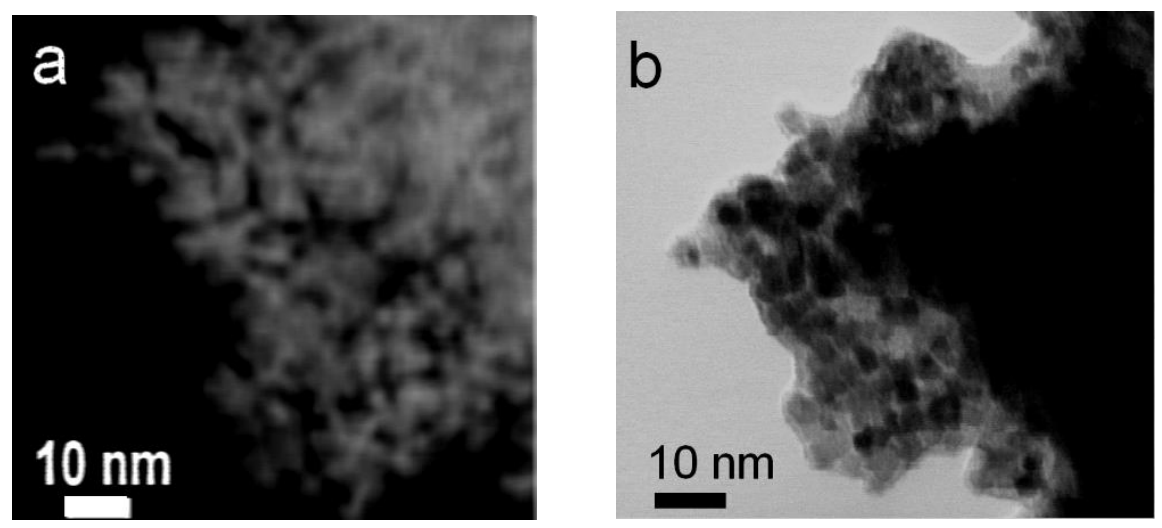

Figure 12: SEM (a) and STEM (b) of the sample 3.

The Raman spectrum of sample 3 contains bands with maxima at $530 \mathrm{~cm}^{-1}$ and $1060 \mathrm{~cm}^{-1}$, which correspond to the spectrum of nickel oxide [56] - Fig. 8 e. It follows from the STEM and Raman data that after annealing sample 1 in air at $1173 \mathrm{~K}$, it is converted into nano dispersed nickel oxide with a particle size near $5 \div 8 \mathrm{~nm}$.

\subsubsection{Sample 4, obtained by annealing sample 1 in an argon atmosphere for 1 hour at $1073 \mathrm{~K}$}

The diffractogram of sample 4 is shown in Fig. 13. It contains low intensity crystalline peaks, the position of which corresponds to the spectrum of crystalline Ni. Also, the diffraction pattern of sample 1 sample 4 has a halo in the region $2 \theta=20 \div 30^{\circ}$, which is characteristic of crystalline carbon materials in a state of a disordered phase [28]. 


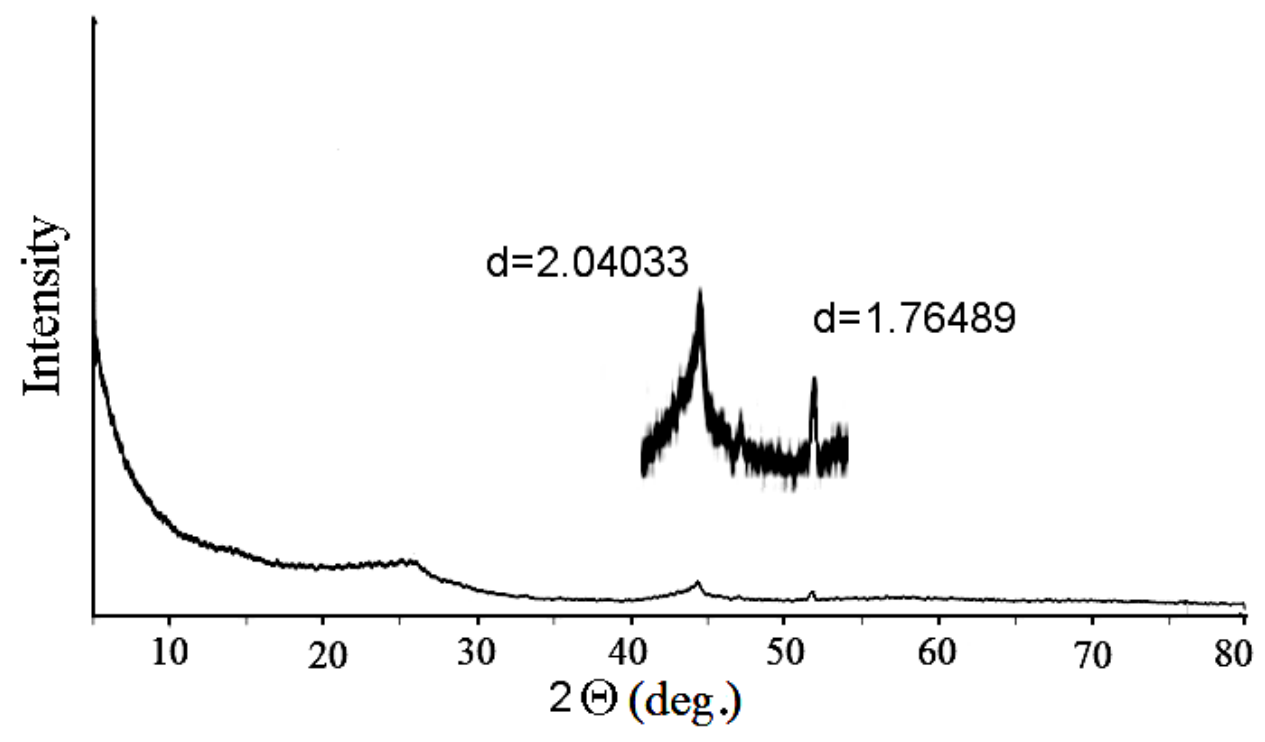

Figure 13: XPA spectrum of sample 4
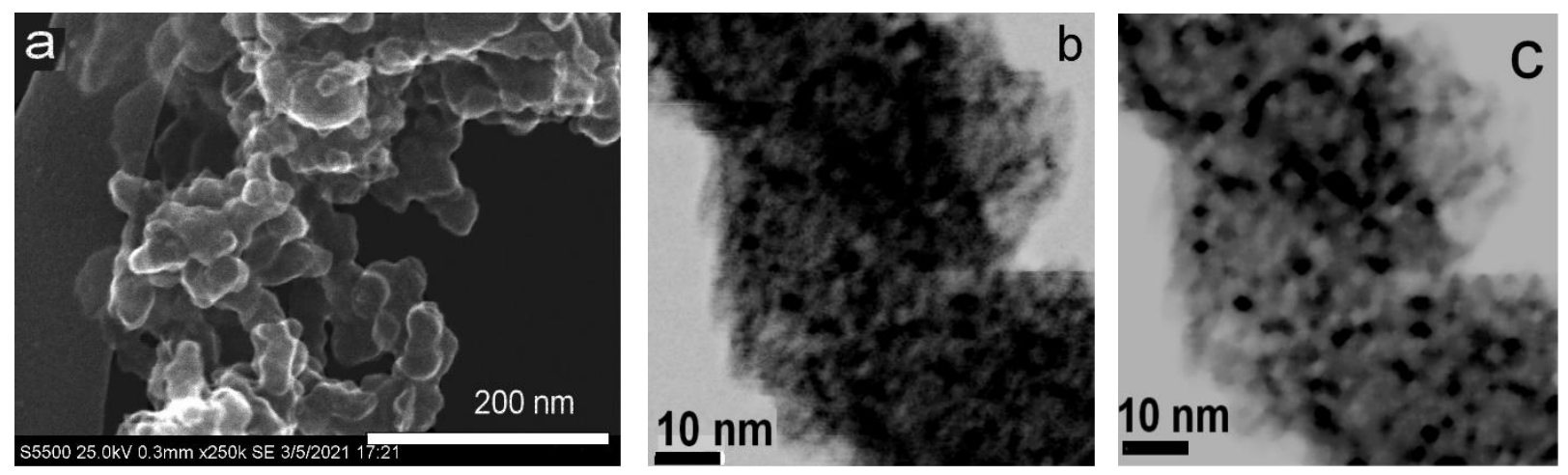

Figure. 14: $\operatorname{SEM}(a)$ and $\operatorname{STEM}(b, c)$ of the sample 4, $(c)$-after digital filtering

As well as sample 1, sample 4 consists of branched and intertwined chain structures built from blocks. Transverse block sizes $50 \div 100 \mathrm{~nm}$ (Fig. 14a). The STEM images of sample 4 show inclusions of particles near $5 \mathrm{~nm}$ in size (Fig. 14 b). It is realistic to assume that these are Ni particles.

The Raman spectra of sample 4 (Fig. 8b) are similar to the spectra of sample 1 (Fig. 8a) and show that, in sample 4, as well as in sample 1, there are nanosized graphitized regions with structural disordering. The sizes of the regions, estimated by the formula of F. Tuinstra and J. Koening, are equal to $\sim 3.5 \mathrm{~nm}$. The IR spectrum of sample 4 is shown in Fig. 6c. The spectrum contains a peak at $1570 \mathrm{~cm}^{-1}$ corresponding to vibrations of double bonds of hexagonal groups in the plane of atomic layers of graphite [34]. The spectrum contains a band at $1726 \mathrm{~cm}^{-1}$ located in the frequency range of vibrations bonds of $-\mathrm{CF}=\mathrm{CF}-$ and $-\mathrm{CF}$ $=\mathrm{CF}_{2}$. In the region where the peaks characteristic of stretching vibrations of $\mathrm{CF}_{2}$ groups in PTFE [33] are expected to be observed, the broad asymmetric band with a maximum at $1231 \mathrm{~cm}^{-1}$ is recorded. Judging by it asymmetry and position and width, it can be assumed that it band is associated with stretching vibrations of $\mathrm{C}-\mathrm{F}$ bonds, which is formed when the molecules of PTFE is disrupted. The similar broaden bands, due to the formation of defects in PTFE molecules, was observed, for example, in PTFE irradiated with argon ions [57].

From the STEM, Raman, and IR data, it follows that after annealing sample 1 in an argon atmosphere at $1173 \mathrm{~K}$, it contains Ni nanoparticles near $5 \mathrm{~nm}$ in size. Particles are scattered throughout the carbon fluorocarbon substance. The carbon portion of sample contains nano-sized graphitized regions. 
Nanocomposite Obtained in the Plasma of a Pulsed High Voltage Discharge Using Nickel Electrodes and PTFE

\subsubsection{Discussion of the results of annealing sample 1 under various conditions}

From the above, it follows that to obtain samples containing $\mathrm{NiO}$ and $\mathrm{Ni}$ nanoparticles with small nanosized sizes, less than $5 \mathrm{~nm}$, method that does not use salts and liquids or special porous matrix was used. Such conditions simplify the experiment and make it possible to quickly obtain samples for research. In the nanocomposites obtained, $\mathrm{NiO}$ and $\mathrm{Ni}$ nanoparticles are located isolated from each other in a carbon-fluorocarbon matrix. This implies the possibility of nanoparticles exhibiting their special properties associated with their nanosize. The matrix contains nanoscale areas of graphite and graphene. It is known that these nanoobjects have been actively studied recently for applications in various fields $[6,26,58]$.

When sample 1 is annealed in air at $1173 \mathrm{~K}$, nickel fluoride contained in $\mathrm{NiF}_{2}$ nanoparticles transforms into $\mathrm{NiO}$. This result requires separate consideration. Direct interaction of $\mathrm{NiF}_{2}$ with $\mathrm{O}_{2}$ in the classical version is not expected since fluorine is the most electronegative element. To resolve this issue, it can be assumed that, under the influence of temperature, $\mathrm{NiF}_{2}$ contained in nanoparticles first loses fluorine and only after that $\mathrm{Ni}$ is oxidized by atmospheric oxygen to $\mathrm{NiO}$. Accordingly, upon annealing sample 1 in an argon atmosphere, fluorine is lost by $\mathrm{NiF}_{2}$ nanoparticles and $\mathrm{Ni}$ nanoparticles are persist and without oxidation. Various mechanisms of the loss of fluorine atoms by $\mathrm{NiF}_{2}$ nanoparticles can be assumed. The simplest option is the loss of fluorine by $\mathrm{NiF}_{2}$ nanoparticles under the influence of temperature. The loss of fluorine can occur, starting from the surface of nanoparticles, on which the bonds of fluorine with $\mathrm{Ni}$ are different from those in the bulk and, possibly, are partially broken and weakened. The percentage of bonds located on the surface of nanoparticles is high; therefore, the removal of fluorine can occur rather intensively.

Another option can be assumed. It is known that the loss of fluorine by metal fluorides can occur during their interaction at high temperatures with fullerenes [59]. It is possible that carbon structures with the same properties as fullerenes are formed in the carbon fluorocarbon matrix of the initial composite obtained by us during its annealing. A significant change in the structure of the carbon matrix of the initial composite can be seen from the data on its annealing in air at $773 \mathrm{~K}$, at which graphene regions are formed in the sample. These data are consistent with our earlier data that various annealing of nanocomposites obtained by the method that used the same way as in this article can form a variety of carbon structures [60]. It can be assumed that the carbon structures formed upon sample annealing, similarly to fullerenes, interact with $\mathrm{NiF}_{2}$ and take fluorine from them.

The investigations of the annealed samples carried out in this work are only preliminary. However, the results already obtained and literature data suggest that further studies of the properties of the obtained nanocomposites and their annealing transformations may can lead to interesting results related to properties of the nanoparticles $\mathrm{NiF}_{2}, \mathrm{NiO}$ and $\mathrm{Ni}$ and nanographite and nanographene.

\section{Conclusions}

Joint consideration of all the data obtained allows us to make the following generalization. Sample 1, obtained in the plasma of the pulsed high-voltage discharge, using nickel electrodes and PTFE, is a nanocomposite containing $\mathrm{NiF}_{2}$ nanoparticles near $5 \div 8 \mathrm{~nm}$ in size, scattered in a matrix of nanosized blocks $50 \div 80 \mathrm{~nm}$ in size composed of carbon and of fluorocarbon components. The carbon component contains amorphous carbon and nanoscale disordered graphite-like structures. The carbon fluoride portion of the sample contains fragments of PTFE molecules and non-PTFE molecular fragments. Non - PTFE fragments contain C-F bonds and double bonds between carbon atoms. The magnetic properties of the obtained composite exhibit features associated with the incorporation of nanosized particles of matter into its composition. This is the temperature hysteresis of the dependences of the magnetic susceptibility recorded in the FC and ZFC modes; the presence of a magnetic exchange bias interaction of the AFM / $\mathrm{FM}$ type at $\mathrm{T}=4 \mathrm{~K}$; the presence of a ferromagnetic phase at $\mathrm{T}=300 \mathrm{~K}$. The composite has an unusual field dependence of the magnetic susceptibility $\mathrm{M}(\mathrm{H})$ at $\mathrm{T}=300 \mathrm{~K}$. With an increase in the magnetic field strength, several reversible abrupt changes in the magnetic susceptibility are observed. The amplitude of the changes decreases with increasing magnetic field strength. The pattern of changes is antisymmetric 
about the $\mathrm{M}$ axis. It is of interest to clarify the nature of these changes. After annealing sample 1 in different atmospheres and at different temperatures, various changes in its chemical composition and morphology take place. After annealing in air at $773 \mathrm{~K}$, a nanocomposite was obtained, consisting of nanoparticles containing nickel fluoride and nickel oxide near $5 \mathrm{~nm}$ in size, scattered in a matrix consisting of nanoscale graphite regions, nanosized grapheme regions, and nanosized PTFE regions. After annealing sample 1 in air at $1173 \mathrm{~K}$, a nano dispersed powder was obtained, consisting of $\mathrm{NiO}$ nanoparticles near $5 \div 8 \mathrm{~nm}$ in size. After annealing the sample in an argon atmosphere at $1073 \mathrm{~K}$, a nanocomposite was obtained consisting of nickel nanoparticles near $5 \mathrm{~nm}$ in size, scattered in a carbon matrix containing nanosized graphitized regions. The transformation of $\mathrm{NiF}_{2}$ nanoparticles into $\mathrm{NiO}$ and $\mathrm{Ni}$ nanoparticles is probably related to their nanosize and their interaction with the matrix. However, this fact requires a more detailed study. The applied methods of obtaining samples are promising for obtaining nanoparticles of metal fluorides, metal oxides and metals with sizes less than $10 \mathrm{~nm}$, as well as for obtaining nanoscale allotropic modifications of carbon.

\section{Competing Interests}

The authors declared that there is no conflict of interest regarding the publication of this manuscript.

\section{How to Cite this Article:}

V. G. Kuryavyi, "Nanocomposite Obtained in the Plasma of a Pulsed High Voltage Discharge Using Nickel Electrodes and PTFE", Adv. Nan. Res., vol. 4, no. 1, pp. 10-26, Oct. 2021. https://doi.org/10.21467/anr.4.1.10-26

\section{References}

[1] T. Hassan, A. Salam, A. Khan, S. U. Khan, H. Khanzada, M. Wasim, M. Q. Khan, I. S. Kim, "Functional nanocomposites and their potential applications: A review", Journal of Polymer Research, vol.28, no. 36, pp. 1-22, 2021. https://doi.org/10.1007/s10965-02102408-1

[2] R. A. M. Said, M. A. Hasan, A. M. Abdelzaher, A, M. Abdel-Raoof, "Review—Insights into the Developments of Nanocomposites for Its Processing and Application as Sensing Materials", Journal of The Electrochemical Society, vol. 167, no.3, pp.1-8, J. Electrochem. Soc., 2020. https://doi.org/10.1149/1945-7111/ab697b

[3] M. M. Shameem, S.M. Sasikanth, R. Annamalai et al., "A brief review on polymer nanocomposites and its applications", Materials Today: Proceedings, vol. 45, pp. 2536-2539, 2021. https://doi.org/10.1016/j.matpr.2020.11.254

[4] A. Ali, T. Shah, R. Ullah, P. Zhou, M. Guo, M. Ovais, Z. Tan, Y. Rui, "Review on Recent Progress in Magnetic Nanoparticles: Synthesis, Characterization, and Diverse Applications", Frontiers in Chemistry, vol. 9, Front. Chem., 2021. https://doi.org/10.3389/fchem.2021.629054

[5] H. Ullah, N. Batisse, K. Guerin, G. Rogez, P. Bonnet, "Synthesis of $\mathrm{NiF}_{2}$ and $\mathrm{NiF}_{2} .4 \mathrm{H}_{2} \mathrm{O}$ Nanoparticles by Microemulsion and Their Self-Assembly”, Langmuir, vol. 36, no. 29, pp.8461-8475, 2020. https://doi.org/10.1021/acs.langmuir.0c00889

[6] N. Baig, I. Kammakakam, W. Falath, "Nanomaterials: a review of synthesis methods, properties, recent progress, and challenges", Materials Advances, vol. 2, iss. 6, pp. 1821-1871, Mater. Adv., 2021. https://doi.org/10.1039/D0MA00807A

[7] S. Hongtao, D. Lederman, K. V. O'Donovan, J. A. Borchers, "Exchange bias and enhancement of the Neel temperature in thin $\mathrm{NiF}_{2}$ films", Physical Review B, vol. 69, iss. 21, pp. 214416, 2004. https://doi.org/10.1103/PhysRevB.69.214416

[8] D. Khomskii, Transition Metal Compounds, Cambridge University Press, ISBN 1107020174, 9781107020177, p. 496, 2015. https://doi.org/10.1557/mrs.2015.188

[9] D.J. Lockwood, M.G. Cottam, "Magnetooptic coupling coefficients for one- and two-magnon Raman scattering in the rutile-structure antiferromagnets $\mathrm{FeF}_{2}, \mathrm{MnF}_{2}, \mathrm{CoF}_{2}$ and $\mathrm{NiF}_{2}$ ", Low Temperature Physics/Fizika Nizkikh Temperatur, vol. 38, iss. 7, pp. 703-714, 2012. https://doi.org/10.1063/1.4733682

[10] J. Khan, H. Ullah, M. Sajjad Co-, A. Bahadar, Z. Bhatti, F. Soomro, F. Hussain Memon, M. Iqbal, F. Rehman, K. Hussain Thebo, "High yield synthesis of transition metal fluorides $\left(\mathrm{CoF}_{2}, \mathrm{NiF}_{2}\right.$, and $\left.\mathrm{NH}_{4} \mathrm{MnF}_{3}\right)$ nanoparticles with excellent electrochemical performance", Inorganic Chemistry Communications, vol. 130, 2021. https://doi.org/10.1016/j.inoche.2021.108751

[11] M. Helen, Maximilian Fichtner, M. Anji Reddy, "Electrochemical synthesis of carbon-metal fluoride nanocomposites as cathode materials for lithium batteries", Electrochemistry Communications, vol. 120, pp. 106846, 2020. https://doi.org/10.1016/j.elecom.2020.106846

[12] Q. Chang, Z. L., Licai Fu, J. Zhu, W. Yang, D. Li, L. Zhou, "A new cathode material of $\mathrm{NiF}_{2}$ for thermal batteries with high specific power”, Electrochimica Acta, vol. 361, pp. 137051, 2020. https://doi.org/10.1016/j.electacta.2020.137051 0013-4686

[13] M. Hafiz, R. Abd-Shukor, "Effect of Nanosized $\mathrm{NiF}_{2}$ Addition on the Transport Critical Current Density of Ag-Sheathed (Bi $\mathrm{Bi}_{1.6}$ $\left.\mathrm{Pb}_{0.4}\right) \mathrm{Sr}_{2} \mathrm{Ca}_{2} \mathrm{Cu}_{3} \mathrm{O}_{10}$ Superconductor Tapes", Advances in Materials Science and Engineering, ID 146476, pp.1-5, 2015. https://doi.org/10.1155/2015/146476

[14] P. Sivaprakash, K. Ashok Kumar, S. Muthukumaran, A. Pandurangan, A. Dixit, S. Arumugam, "NiF 2 as an efficient electrode material with high window potential of $1.8 \mathrm{~V}$ for high energy and power densityasymmetric supercapacitor", Journal of Electroanalytical Chemistry, vol. 873, 114379, 2020. https://doi.org/10.1016/j.jelechem.2020.114379 
[15] V.G. Kuryavyi, I.A. Tkachenko, A.Yu. Ustinov, V.M. Bouznik, "The composite containing nanosized FeF 3 and $\mathrm{CrF}_{3}$, aluminium compound, and carbon components synthesized in pulse high-voltage discharge plasma and its magnetic properties", Sciences of Europe, vol. 4, no. 4, pp. 38-42, 2016.

[16] V.G. Kuryavyi, V.M. Buznik, A.Yu. Ustinov, S.A. Sukhoverkhov, A.D. Pavlov, A.B. Slobodyuk, I.A. Tkachenko, A.A. Kvach, T.A. Kaidalova, "Nanocomposite Synthesized in Plasma of Pulse High-Voltage Discharge Initiated between Copper Electrodes in the Presence of Fluoroplast", Inorganic Materials: Applied Research, vol. 10, no. 1, pp. 184-194, 2019. https://link.springer.com/article/10.1134/S2075113319010179

[17] Y. Shi, M. Shen, S. Xu, X. Qiu, L. Jiang, Y. Qiang, Q. Zhuang, S. Sun, "Electrochemical Impedance Spectroscopic Study of the Electronic and Ionic Transport Properties of $\mathrm{NiF}_{2} / \mathrm{C}$ Composites", Int. J. Electrochem. Sci., vol. 6, no. 8, pp. 3399-3415, 2011.

[18] L. Doubtsof, P. Bonnet, L. Jouffret, K. Guérin, "The Influence of Sacrificial Carbonaceous Supports on the Synthesis of Anhydrous $\mathrm{NiF}_{2}$ Nanoparticles", Chemistry Select, vol. 1, iss. 16, pp. 5172-5181, 2021. https://doi.org/10.1002/slct.201601306

[19] V. Tripathi , H. Kumar, A. Agarwal, L. S. Panchakarla, J.Beilstein, "Microwave-induced electric discharges on metal particles for the synthesis of inorganic nanomaterials under solvent-free conditions", Nanotechnology, vol. 11, pp. 1019-1025, 2020. https://doi.org/10.3762/bjnano.11.86

[20] S. Uddin, L. B. Safdar, S. Anwar, J. Iqbal, S. Laila, B. A.n Abbasi, M. S. Saif, M. Ali, A. Rehman, A. Basit, Y. Wang, U. M. Quraishi, "Green Synthesis of Nickel Oxide Nanoparticles from Berberis balochistanica Stem for Investigating Bioactivities", Molecules, vol. 26, iss. 6, 2021. https://doi.org/10.3390/molecules26061548

[21] T. Merciris, F. Valensi, A. Hamdan, "Synthesis of nickel and cobalt oxide nanoparticles by pulsed underwater spark discharges", Journal of Applied Physics, vol. 129, iss. 6, 063303, 2021. https://doi.org/10.1063/5.0040171

[22] M. A. J. Kouhbanani, Y. Sadeghipour, M. Sarani, E. Sefidgar, S. Ilkhani, A. M. Amani, N. Beheshtkhoo, The inhibitory role of synthesized Nickel oxide nanoparticles against Hep-G2, MCF-7, and "HT-29 cell lines: the inhibitory role of NiO NPs against HepG2, MCF-7, and HT-29 cell lines", Chemistry Letters And Reviews, vol. 14, no. 3, pp. 443-453, 2021. https://doi.org/10.1080/17518253.2021.1939435

[23] N. Jaji, H. L. Lee, M. H. Hussin, H. M. Akil, M. R. Zakaria, M. B. H. Othman, “Advanced nickel nanoparticles technology: From synthesis to applications", Nanotechnology Reviews, vol. 9, pp. 1456-1480, 2020. https://doi.org/10.1515/ntrev-2020-0109

[24] AA. Adam, M. Szabados, G. Varga, A. Papp, K. Musza, Z. Konya, "Ultrasound-assisted hydrazine reduction method for the preparation of nickel nanoparticles, physicochemical characterization and catalytic application in Suzuki-Miyaura cross-coupling reaction", Nanomaterials, vol. 10, iss. 4, pp. 632-649, 2020. https://doi.org/10.3390/nano10040632

[25] L. Xiaohan, W. Gehui, “NiO@C and Ni@C Nanoparticles: Synthesis, Characterization and Magnetic Properties”, Nano Brief Reports and Reviews, vol. 15, no. 06, 2050072, 2020. https://doi.org/10.1142/S1793292020500721

[26] Jianling Meng, Dongxia Shi, Guangyu Zhang, "A review of nanographene: growth and applications", Modern Physics Letters B, Vol. 28, No. 20, 1430009, 2014. https://doi.org/10.1142/S0217984914300099

[27] Lebedev, Yu.M Korolev, A.V. Rebrov, L.N. Ignat'eva, E.M. Antipov, "X-ray diffraction phase analysis of the crystalline phase of polytetrafluoroethylene", Crystallography Reports, vol.55, no. 4, pp. 615-620, Crystallogr. Rep., 2010. https://doi.org/10.1134/S1063774510040139.

[28] Z.Q. Li, C.J. Lu, Z.P. Xia, Y. Zhou, Z. Luo, "X-ray diffraction patterns of graphite and turbostratic carbon", Carbon, vol. 45, no.8, pp. 1686-1695, 2007. https://doi.org/10.1016/j.carbon.2007.03.038

[29] J.E. Wertz, J.R. Bolton. Electron Spin Resonance. Elementary Theory and Practical Applications. Springer Science+Business Media B.V., 500 p., 1986. https://www.springer.com/gp/book/9789401083072.

[30] H. J. Bardeleben, J. L. Cantin, A. Zeinert, B. Racine, K. Zellama, P. N.Hai, "Spins and microstructure of hydrogenated amorphous carbon: A multiple frequency electron paramagnetic resonance study", Applied Physics Letters, vol. 78, pp. 2843, Appl. Phys. Lett., 2001. https://doi.org/10.1063/1.1370980.

[31] T.H. Dufour, N. Vandencasteele, S. Desbief, R. Lazzaroni, F.Reniers, "Etching Processes of Polytetrafluoroethylene Surfaces Exposed to $\mathrm{He}$ and He-O2 Atmospheric Post-discharges”, Langmuir, vol. 28, pp. 9466-9474, 2012. https://doi.org/10.1021/la300822j.

[32] V.N. Mitkin, "Types of inorganic fluorocarbon polymer materials and structure-property correlation problems", Journal of Structural Chemistry, vol. 44, pp. 82-115, J. Struct. Chem., 2003. https://doi.org/10.1023/A:1024989132154

[33] V.M. Bouznik, V.M. Fomin, A.P. Alkhimov, L.N. Ign atieva, Metallopolimernye Nanokompozity (Polucheniye, Svoystva, Primeneniye), Izd-vo SO RAS, 260 p., 2005.

[34] R. Setton, P. Bernier, S. Lefrant. Carbon molecules and materials. L.-N.Y.: Taylor @ Francis, 512 p., 2002.

[35] K.Ikeda, Y.Kubo, K.Okamoto, "Elucidation of Molecular Structure and Adhesion State of Cross-Linked Fluororesin", SEI Technical Review, vol. 196, pp. 42-57, 2020.

[36] V.Wray, "F-19 NMR Spectroscopy", Annual Reports NMR Spectroscopy, vol. 10B, no. 1, 1980.

[37] O.A. Maslova, M.R. Ammar, G. Guimbretiere, J.-N. Rouzaud, P. Simon, "Determination of crystallite size in polished graphitized carbon by Raman spectroscopy", Physical Review B, vol. 86, iss. 13, pp. 134205-5, 2012. doi:10.1103/PhysRevB.86.134205.

[38] F.Tuinstra, J.Koenig, "Raman spectrum of graphite", Journal of Chemical Physics, vol. 53, iss. 3, pp. 1126-1130, J. Chem. Phys., 1970. https://doi.org/10.1063/1.1674108

[39] C. D' 'az, M. L. Valenzuela, M.A. Laguna-Bercero, A. Orera, D. Bobadilla, S. Abarcaa, O. Pena, "Synthesis and magnetic properties of nanostructured metallic Co, Mn and Ni oxide materials obtained from solid-state metalmacromolecular complex precursors", RSA Advanced, iss. 44, pp. 27729-27736, 2017. https://doi.org/10.1039/c7ra00782e.

[40] T. Makarova, F. Palacio, Carbon Based Magnetism: An Overview of the Magnetism of Metal Free Carbon-based, Compounds and Materials, pp. 576, 2006. https://www.elsevier.com/books/carbon-based-magnetism/makarova/978-0-444-51947-4

[41] G.A. Petrakovskii, "Spin glasses”, Sorosovskii obrazovatelnii Zhurnal, vol. 7, no. 9, pp. 83-89, 2001. 
Kuryavyi et al., Adv. Nan. Res.; Vol. 4, Issue 1, pp: 10-26, 2021

[42] S.P. Gubin, Yu.A. Koksharov, G.B. Khomutov, G.Yu Yurkov, "Magnetic nanoparticles: preparation, structure and properties", Russian Chemical Reviews, vol. 74, no. 6, pp. 489-520, Russ. Chem. Rev., 2005. https://doi.org/10.1070/RC2005v074n06ABEH000897.

[43] V.I. Belokon, K.V .Nefedov, M.A.Savunov, "Finite interaction range spin glass in the Ising model", Physics of the Solid State, vol. 48, iss. 9, pp.1746-1753, Phys. Solid State., 2006. https://doi.org/10.1134/S106378340609023X

[44] I.J. Bruvera, M.P. Zélis, M.P. Calatayud, G. Goya, F. H.Sánchez, "Determination of the blocking temperature of magnetic nanoparticles: The good, the bad, and the ugly", Journal of Applied Physics, vol. 118, iss. 18, pp. 184304-7, 2015. https://doi.org/10.1063/1.4935484

[45] L .M. Matarrese, J.W. Stout, "Magnetic Anisotropy of $\mathrm{NiF}_{2}$ ", Physical Review, vol. 94, 1954. pp. 1792, Phys. Rev. https://doi.org/10.1103/PhysRev.94.1792

[46] W.H. Meiklejohn, C.P. Bean, "New magnetic anisotropy”, Physical review, vol. 102, iss. 5, pp. 1413-1414, Phys. Rev. 1956. https://doi.org/10.1103/PhysRev.102.1413

[47] G. Magda, X. Jin, I. Hagymasi, P.V ancso, Z.O svath, P. Nemes-Incze, C. Hwang, L.P. Biro, L. Tapaszto, "Room-temperature magnetic order on zigzag edges of narrow graphene nanoribbons", Nature, vol. 514, no. 7524, pp. 608-611. https://doi.org/10.1038/nature13831.

[48] J. Heremans, C. H. Olk, D. T. Morelli, "Magnetic susceptibility of carbon structures", Physical review B, vol. 49, iss. 21, pp. 1512215125, J. Phys Rev B, 1994. https://doi.org/10.1103/PhysRevB.49.15122.

[49] S.G. Lebedev, "Carbon superconductivity", Priroda, vol. 8, pp. 38-44, 2007.

[50] N.B. Brandt, S.V. Kuvshinnikov, A.P. Rusakov, M.V. Semenov, "Anomalous diamagnetism (high-temperature Meissner effect) in the compound CuCl", Pisma Zh. Eksp. Teor. Fiz., vol. 27, iss. 21, pp. 37-43, 1978.

[51] L.R. Shi, Z.C. Xia, Z. Jin, M. Wei, J.W. Huang, B.R .Chen, L.X. Xiao, H.K. Zuo, Z.W. Ouyang, "High magnetic field induced spin flip/flop behavior and magnetic phase diagram of $\mathrm{CuFe}_{1-\mathrm{x}} \mathrm{GaxO}_{2}$ ", Journal of Solid State Chemistry, vol. 219, pp. 152-158, 2014. https://doi.org/10.1016/j.jssc.2014.07.028

[52] A.N. Bogdanov, A.V. Zhuravlev, U.K. R"oßler, "Spin-flop transition in uniaxial antiferromagnets: magnetic phases, reorientation effects, multidomain states", Physical review B, Condensed matter, vol. 75, iss. 9, pp. 1-15, 2007. https://doi.org/10.1103/PhysRevB.75.094425.

[53] M.S. Seehra, U.K. Geddam, D. Schwegler-Berry, A.B. Stefaniak, "Detection and quantification of $2 \mathrm{H}$ and 3R phases in commercial graphene-based materials", Carbon, vol. 95, pp. 818-823, 2015. https://doi.org/10.1016/j.carbon.2015.08.109

[54] K.S. Subrahmanyam, S.R. C.Vivekchand, A. Govindaraj, C.N.R. Rao, "A study of graphenes prepared by different methods: characterization,properties and solubilization", Journal of Materials Chemistry, vol.18, pp. 604-610, Mater. Chem., 2008. https://doi.org/10.1039/b716536f

[55] A.C. Ferrari, "Raman spectroscopy of graphene and graphite: Disorder, electron-phonon coupling, doping and nonadiabatic effects". Solid State Comm, vol. 143, iss. 1-2, pp. 47-57, 2007. https://doi.org/10.1016/j.ssc.2007.03.052

[56] F. Chandoul, H .Moussa, K. Jouini, A. Boukhachem, F. Hosni, M.S. Fayache, R. Schneider, "Investigation of the properties of nanostructured nickel oxide $\mathrm{NiO}$ thinfilms irradiated at different $\gamma$-doses NiO", Journal of Materials Science: Materials in Electronics, vol. 30, pp. 348-358, 2019. https://link.springer.com/article/10.1007/s10854-018-0299-z

[57] D.V. Shtanskij, N.A. Glushankova, F.V. Kirjuhancev-Korneev, A.N. Shevejk, A.A. Sigarev, "Sravnitel'noe issledovanie struktury i citotoksichnosti politetraftorjetilena posle ionnogo travlenija i ionnoj implantacii”, Fizika tverdogo tela, vol. 53, no. 3, pp. 13-14, 2011 .

[58] J. Meng, D. Shi, G. Zhang. "A review of nanographene: growth and applications", "Modern Physics Letters B", vol. 28, no. 20, 1430009, 2014. https://doi.org/10.1142/S021798491430009

[59] A. Ju. Lukonin, V. Ju. Markov, O. V. Boltalina, "Sintez ftorfullerenov v reakcijah s neorganicheskimi ftoridami", Vestnik Moskovskogo Universiteta, vol. 42, no.1, 2001.

[60] V.G. Kuryavyi, V.M. Bouznik, Y. N. Nikolenko, O.O. Shichalin, "Forms of carbon obtained from PTFE by processing in plasma of pulsed high-voltage discharge and then annealing", Materials Today: Proceedings, vol. 5, pp. 26166-26170, 2018. https://doi.org/10.1016/j.matpr.2018.08.048

Publish your research article in AIJR journals-

$\checkmark \quad$ Online Submission and Tracking

$\checkmark$ Peer-Reviewed

$\checkmark$ Rapid decision

$\checkmark \quad$ Immediate Publication after acceptance

$\checkmark$ Articles freely available online

$\checkmark$ Retain full copyright of your article.

Submit your article at journals.aijr.org

\section{Publish your books with AIJR publisher-}

$\checkmark \quad$ Publish with ISBN and DOI.

$\checkmark$ Publish Thesis/Dissertation as Monograph.

$\checkmark$ Publish Book Monograph.

$\checkmark$ Publish Edited Volume/ Book.

$\checkmark$ Publish Conference Proceedings

$\checkmark \quad$ Retain full copyright of your books.

Submit your manuscript at books.aijr.org 